\title{
GEOPHYSICAL CONSTRAINTS ON THE EVOLUTION OF MARS
}

\author{
TILMAN SPOHN ${ }^{1}$, MARIO H.ACUÑ ${ }^{2}$, DORIS BREUER ${ }^{1}$, MATTHEW \\ GOLOMBEK $^{3}$, RONALD GREELEY ${ }^{4}$, ALEXANDER HALLIDAY ${ }^{5}$, ERNST \\ HAUBER $^{6}$, RALF JAUMANN ${ }^{6}$ and FRANK SOHL ${ }^{1}$ \\ ${ }^{1}$ Institut für Planetologie, Westfälische Wilhelms-Universität, \\ W. Klemmstrasse 10, D-48149 Münster, Germany \\ ${ }^{2}$ NASA Goddard Space Flight Center, Greenbelt, MD 20771; USA \\ ${ }^{3}$ Jet Propulsion Laboratory, Pasadena, Ca 91109, USA \\ ${ }^{4}$ Department of Geology, Arizona State University, Tempe, AZ 85287-1404, USA \\ ${ }^{5}$ Department of Earth Sciences, ETH Zentrum, CH-8092 Zürich, Switzerland \\ ${ }^{6}$ Deutsches Zentrum für Luft- und Raumfahrt DLR, D-12489 Berlin, Germany
}

Received: 28 November 2000; accepted: 28 February 2001

\begin{abstract}
The evolution of Mars is discussed using results from the recent Mars Global Surveyor (MGS) and Mars Pathfinder missions together with results from mantle convection and thermal history models and the chemistry of Martian meteorites. The new MGS topography and gravity data and the data on the rotation of Mars from Mars Pathfinder constrain models of the present interior structure and allow estimates of present crust thickness and thickness variations. The data also allow estimates of lithosphere thickness variation and heat flow assuming that the base of the lithosphere is an isotherm. Although the interpretation is not unambiguous, it can be concluded that Mars has a substantial crust. It may be about $50 \mathrm{~km}$ thick on average with thickness variations of another \pm 50 $\mathrm{km}$. Alternatively, the crust may be substantially thicker with smaller thickness variations. The former estimate of crust thickness can be shown to be in agreement with estimates of volcanic production rates from geologic mapping using data from the camera on MGS and previous missions. According to these estimates most of the crust was produced in the Noachian, roughly the first Gyr of evolution. A substantial part of the lava generated during this time apparently poured onto the surface to produce the Tharsis bulge, the largest tectonic unit in the solar system and the major volcanic center of Mars. Models of crust growth that couple crust growth to mantle convection and thermal evolution are consistent with an early 1 Gyr long phase of vigorous volcanic activity. The simplest explanation for the remnant magnetization of crustal units of mostly the southern hemisphere calls for an active dynamo in the Noachian, again consistent with thermal history calculations that predict the core to become stably stratified after some hundred Myr of convective cooling and dynamo action. The isotope record of the Martian meteorites suggest that the core formed early and rapidly within a few tens of Myr. These data also suggest that the silicate rock component of the planet was partially molten during that time. The isotope data suggest that heterogeneity resulted from core formation and early differentiation and persisted to the recent past. This is often taken as evidence against vigorous mantle convection and early plate tectonics on Mars although the latter assumption can most easily explain the early magnetic field. The physics of mantle convection suggests that there may be a few hundred km thick stagnant, near surface layer in the mantle that would have formed rapidly and may have provided the reservoirs required to explain the isotope data. The relation between the planform of mantle convection and the tectonic features on the surface is difficult to entangle. Models call for long wavelength forms of flow and possibly a few strong plumes in the very early evolution. These plumes may have dissolved with time as the core cooled and may have died off by the end of the Noachian.
\end{abstract}

Space Science Reviews 96: 231-262, 2001.

(C) 2001 Kluwer Academic Publishers. Printed in the Netherlands. 


\section{Introduction}

Like that of any other planet, the evolution of Mars is to a large extent determined by its interior structure and composition and by its material properties. A significant part of these quantities can be measured applying geophysical methods at the planet, in orbit or in situ. Moreover, model calculations and laboratory measurements are instrumental.

Mars is among the best explored planets, second only to the Earth and Moon, thanks to the number of missions to the planet and thanks to the significant interest it has attracted, not the least because of its similarity in various respects with the Earth. Among the most important recent accomplishments in terms of planetary physics (borrowing to some extent from cosmochemistry) are the

- accurate measurement of the topography through laser ranging by Mars Global Surveyor (MGS) (Smith et al., 1999a).

- measurement and mapping of the gravity field through two-way Doppler tracking of the MGS spacecraft (Smith et al., 1999b).

- determination of the precession rate of the rotational axis by Mars Pathfinder (Folkner et al., 1997).

- detection and measurement of remnant magnetisation in the southern hemisphere (Acuña et al., 1998).

- identification of young lava flows $(<100 \mathrm{Myr})$ in Mars Observer Camera (MOC) images (Hartmann et al., 1999).

- in situ measurement of the composition of Martian rock and soil by Mars Pathfinder and detection of rock that is similar in composition to terrestrial andesites (Rieder et al., 1997).

- detection and mapping of two crustal rock types, basaltic and andesitic, on the surface by MGS (Bandfield et al., 2000).

The first three items above constrain interior structure. From the first two, models of crust and lithosphere thickness were derived (Zuber et al., 2000). The third allowed an accurate measurement of the moment-of-inertia factor (MoI-factor) which, together with the mass of the planet is the most important geophysical piece of data to constrain global models of interior structure. The MoI-factor is defined as the dimensionless ratio between the moment of inertia of the planet about the rotation axis divided by the mass and the square of the planet radius.

The last four discoveries listed above constrain models of the evolution of the planet: The remnant magnetization of the southern hemisphere crust strongly suggests that the planet once had a self-sustained magnetic field which it is lacking at the present time. Crustal units devoid of magnetization must have formed when the dynamo was not active. The detection of young lava flows of less than $100 \mathrm{Myr}$ of age suggests that the planet has been volcanically active up to the recent past. This observation ties in nicely with the young crystallization ages of the Shergottite meteorites from Mars (Nyquist et al., 2001; Halliday et al., 2001). The detection of two chemical components in Martian rock, one basaltic like the composition 
of the Martian meteorites and one more silica rich (Wänke et al., 2001), constrains models of the mantle and its differentiation history. Apparently, differentiation may have employed crust recycling and remelting. Thermal Emission Spectrometer TES data from the MGS mission (Bandfield et al., 2000) suggest that there is a dichotomy in the composition of the surface rock with the northern hemisphere being largely composed of the silica rich (or andesitic) component and the southern hemisphere dark regions largely basaltic. This observation indicates a striking albeit yet little understood difference in evolution between the two hemispheres that goes well beyond their difference in age (Hartmann and Neukum, 2001).

The geologic features of the planet can be briefly characterized as such: Mars is a one-plate planet, lacking any sign of present-day plate tectonics. Rather, its deep interior is likely covered by a one-plate lithosphere which in places is pierced by volcanic vents that may sample the sublithosphere layers. The most prominent topographic features of the surface (Figure 2 of Hartmann et al., 2001) are the dichotomy between the northern and the southern hemispheres, the Tharsis bulge and the Hellas impact basin. While the southern hemisphere is heavily cratered, the northern hemisphere is cratered to a much lesser extent and, therefore, younger. The Tharsis bulge, a gigantic volcanic and tectonic region likely formed during the early evolution of the planet and persisted and has been active unto the recent past. The formation of the Tharsis bulge and the volcanic activity associated with it is a major challenge for planetary modeling. The Hellas basin is the largest, deepest and most prominent impact basin on Mars.

We begin this review by summarizing observational constraints on Mars evolution models and then we discuss the results of model calculations. These constraints are as presently understood for the volcanic and tectonic history, the crust and lithosphere thicknesses, the structure of the deep interior and the magnetic field. We conclude the article by pointing out major open questions that remain to be solved through further exploration of the planet including seismic exploration and modeling of its interior dynamics and evolution.

\section{Observational Constraints on Evolution Models}

\subsection{TOPOGRAPHY AND GRAVITY}

The topography of Mars and its gravity field have recently been measured with much improved accuracy over previous data by the MOLA and Radio Science teams on Mars Global Surveyor, (e.g., Smith et al., 1999a, 1999b, 2000; Zuber et $a l ., 2000)$. The presently available new topography model has a spatial resolution of $1 / 32^{\circ}$ by $1 / 64^{\circ}(\approx 2$ by $4 \mathrm{~km})$ and an absolute accuracy of $13 \mathrm{~m}$ with respect to the center of mass. The gravity field measured by X-band Doppler tracking of the MGS spacecraft has a spatial resolution of about $178 \mathrm{~km}$ and an accuracy of \pm 10 $\mathrm{mGal}\left(10^{-5} \mathrm{~m} \mathrm{~s}^{-2}\right)$ at the poles, $\pm 20 \mathrm{mGal}$ at the equator, and $\pm 100 \mathrm{mGal}$ over the Tharsis Montes and Olympus Mons. 


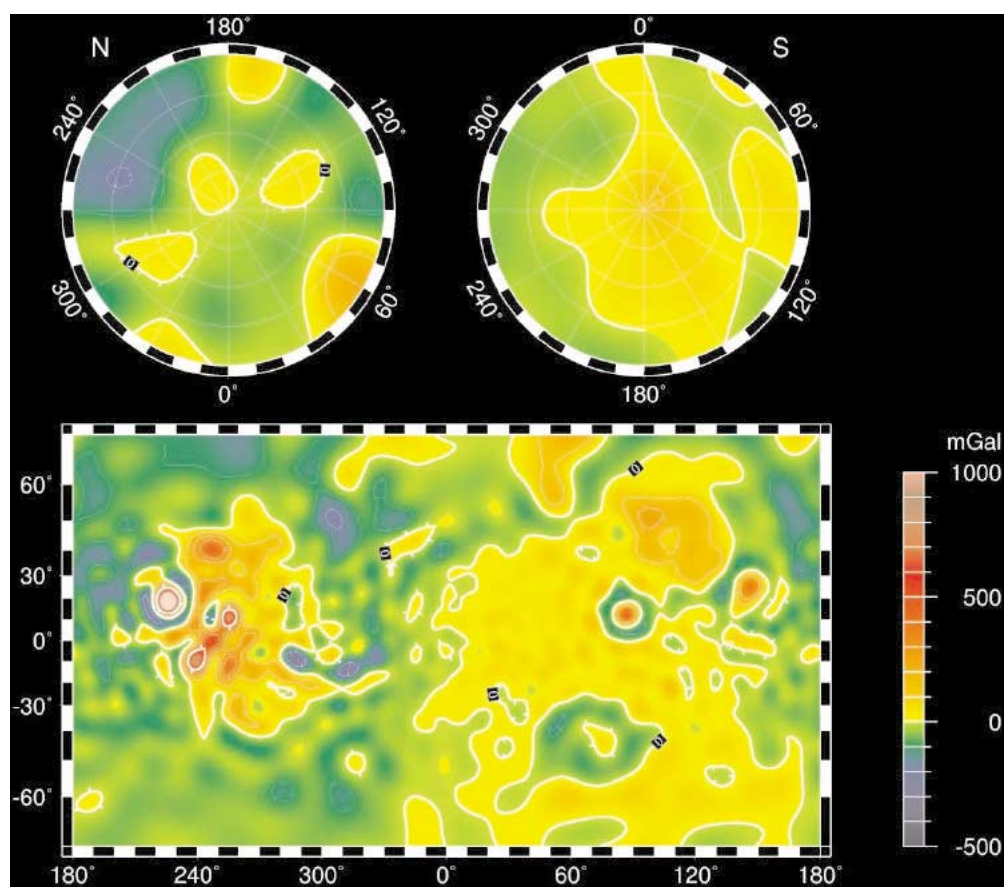

Figure 1. MGS (free air) gravity field from Smith et al. (1999a)

The topography of Mars exhibits a clear dichotomy which divides the surface into a southern highland hemisphere (about $60 \%$ of the surface) rising several thousands of meters above the zero level and a northern lowlands hemisphere well below the datum. The most prominent features besides the dichotomy are the Tharsis bulge and the Hellas impact basin (compare Figure 2 of Hartmann et al., 2001). The Tharsis bulge is of enormous size covering the entire western hemisphere of the planet and rising $10 \mathrm{~km}$ above the datum. The topographic data reveal that Tharsis actually consists of two parts, a larger nearly circular feature that contains the Tharsis volcanoes in the south and an elongated rise in the north that contains Alba Patera. The southern rise extends onto the southern highlands while the northern rise is in the lowlands. The southern Tharsis province contains a scorpion-tail shaped ridge that is apparently considerably older, of Noachian age (see Section 2.3.1 below, for a brief definition of the Martian stratographic time system), and has not been flooded by the Tharsis volcanic material. A significant part of the Martian topography can be correlated with a roughly $3 \mathrm{~km}$ center of mass - center of figure offset southward along the polar axis (Smith et al., 2000). When the COM-COF offset is subtracted from the topography, the Tharsis province stands even further out (Smith et al., 1999a). In this representation, the topography shows a $\ell=2$ characteristics, a chain of highs and lows that circle Mars' equator.

The (free air) gravity field (Figure 1) is generally rather smooth although it is rougher in the northern hemisphere than in the southern hemisphere. Peaks in 
gravity at the Tharsis and Elysium volcanoes indicate that these are not compensated, i.e. not in isostatic equilibrium. Major features of the (free air) gravity field include a broad complex shaped high over Tharsis and a similar high over Isidis. There is no clear association with the dichotomy boundary. The Valles Marineris canyon system is clearly visible on the gravity map as a chain of deep lows on the Eastern flank of Tharsis. Large impact basins such as Hellas and Syrtis Major are characterized by relative highs surrounded by rings of lows.

The topography and gravity data from the MGS mission have been interpreted in terms of crust and elastic lithosphere thickness models (Zuber et al., 2000). Moreover, the variation of the surface heat flow has been estimated from the lithosphere thickness map. Due to the inherent non-uniqueness in any interpretation of gravity data, these models rely on additional assumptions such as constant crust and mantle densities and average crustal thickness. Nevertheless, crust and lithosphere thickness estimates constrain models of cooling and thermo-chemical evolution.

A rough estimate of crustal thickness variation and mean crust thickness can be derived from the simple assumption of Airy isostasy and the amplitudes of the topography variations. (Airy isostasy assumes that the crust is of homogeneous density and that, in equilibrium, any variations of topography are compensated by equivalent variations of crust thickness. Pratt isostasy, an alternative model, assumes that the topography is caused by lateral variations in crust density). In an Airy model the crustal thickness variation is simply $\left(1-\rho_{\mathrm{c}} / \rho_{\mathrm{m}}\right)^{-1}$ times the amplitude of the topography variation where $\rho_{\mathrm{c}}$ is the crust density and $\rho_{\mathrm{m}}$ the mantle density. Assuming $2900 \mathrm{~kg} \mathrm{~m}^{-3}$ for $\rho_{\mathrm{c}}$ and $3500 \mathrm{~kg} \mathrm{~m}^{-3}$ for the density of the mantle on which the crust is assumed to float, $\left(1-\rho_{\mathrm{c}} / \rho_{\mathrm{m}}\right)^{-1}$ is about 6 and with a total variation of the topography of roughly $20 \mathrm{~km}$ a thickness variation of 120 $\mathrm{km}$ is obtained. Assuming further that the crust thickness is approximately zero underneath the deepest regions (the large impact basins such as Hellas) and that the zero topography level is representative of the average crust, an average crustal thickness of about $50 \mathrm{~km}$ is calculated from the roughly $8 \mathrm{~km}$ depth of the Hellas Basin. This crust comprises about $4.4 \%$ of the planet's volume.

A more sophisticated approach (Wieczorek and Phillips, 1998; Zuber et al., 2000) uses the (Bouguer) gravity map to calculate crustal thickness variations under the assumption of Airy isostasy. The model crust map of Zuber et al. (2000) is based on an assumed constant crustal density of $2900 \mathrm{~kg} \mathrm{~m}^{-3}$, a constant mantle density of $3500 \mathrm{~kg} \mathrm{~m}^{-3}$ and an assumed average crust thickness of $50 \mathrm{~km}$. This yields a maximum thickness of the crust of $92 \mathrm{~km}$ underneath Syria Planum and a minimum thickness of $3 \mathrm{~km}$ beneath the Isidis basin. The model crust thickness is roughly constant underneath the northern lowlands and Arabia Terra at a thickness of $40 \mathrm{~km}$ and increases underneath the southern highlands towards the south pole to reach a thickness of $\sim 70 \mathrm{~km}$. The average crust thickness of $50 \mathrm{~km}$ is a minimum thickness, assuming that the crust covers the whole planet. A problem with the assumption of Airy isostasy is that in perfect equilibrium the (free air) gravity should be uncorrelated with topography, which in general is not the case on Mars. 
Sohl and Spohn (1997) have derived average crustal thicknesses of more than $100 \mathrm{~km}$ in their models of the global structure which are based on the Martian meteorite chemistry, the MoI-factor and the mass using the same crust and upper mantle average densities. (Note that the Zuber et al. and the Sohl and Spohn models differ in the constraints used.) Zuber et al. (2000) argue that a crust of this thickness could not sustain the inferred low order crustal thickness variations over the planet's history. Rather, crustal thickness variations would relax unless the viscosity of the lower crust were larger than $10^{22} \mathrm{~Pa} \mathrm{~s}$. A crust of $50 \mathrm{~km}$ thickness could be maintained for more than $10^{8}$ years if the viscosity of the lower crust was more than $10^{20} \mathrm{~Pa} \mathrm{~s}$. While this argument is reasonable, it is not entirely convincing in supporting a $50 \mathrm{~km}$ crust with Airy-model thickness variations of approximately $\pm 50 \mathrm{~km}$. A possible alternative is the suggestion of lateral density variations as in the Pratt-model. Again we make an argument based on a simple model. With Prattisostasy the density variation $\Delta \rho$ to support a given topography variation $\Delta T_{\mathrm{op}}$ is $\bar{\rho}\left(\bar{z} / \Delta T_{\mathrm{op}}+1\right)^{-1}$ where $\bar{z}$ is the average crust thickness. Assuming $100 \mathrm{~km}$ and $3000 \mathrm{~kg} \mathrm{~m}^{-3}$ for the average crust thickness and density, respectively, and taking the topography variations to be $\pm 5 \mathrm{~km}$ thereby ignoring the largest variations associated with large impact basins and volcanoes, we require a $\Delta \rho$ of a modest $\pm 150 \mathrm{~kg} \mathrm{~m}^{-3}$. This value would bring the density of the lowland crust close to (but still smaller than) the densities of the SNC meteorites of 3230 to $3350 \mathrm{~kg} \mathrm{~m}^{-3}$ and would require a density in the highland crust of $2850 \mathrm{~kg} \mathrm{~m}^{-3}$. The crustal thickness variations in this model would be small, about equal to the topography variations. Therefore, the model avoids the difficulty of maintaining substantial crustal thickness variations over geologic history against viscous relaxation. We will not claim that this model should apply to the entire Martian crust, however. For instance, it is reasonable to assume crustal thinning caused by mantle rebound underneath large impact basins. Rather, we stress the potential importance of lateral crust density and chemistry variations and the non-uniqueness of gravity models. A seismic network on Mars like the one to be installed by the European Netlander mission presently under development (Harri et al., 2000) will certainly help to provide more reliable crustal thickness models.

Using both topography and gravity data, Zuber et al. (2000) have calculated the Martian effective elastic lithosphere thickness, which can be understood as the thickness of the coldest outermost layer of the planet that supports stresses over geologically long time scales. This effective lithosphere thickness varies considerably over the Martian surface and not always as one might expect. The thickest lithosphere values of $\sim 200 \mathrm{~km}$ are found at the largest volcanoes Olympus Mons, Pavonis Mons (a Tharsis volcano) and Tharsis in general; the smallest values are at Arabia Terra and Nochis Terra. Generally, the southern hemisphere shows small values of $\sim 20 \mathrm{~km}$ while typical values for the Northern hemisphere are $\sim 100 \mathrm{~km}$. Since the calculation applies models of elastic lithosphere flexure it is argued that the lithosphere thicknesses are actually the thicknesses at the time of loading, an interpretation that has been successfully used on Earth. Consequently, the elastic 
lithosphere has increased from $20 \mathrm{~km}$ during the time of formation of the units on the southern hemisphere to $\sim 100 \mathrm{~km}$ at the time of formation of units on the northern hemisphere. Loading by the Tharsis volcanoes, according to this hypothesis, occurred at a time when the elastic lithosphere was already more than $100 \mathrm{~km}$, $\sim 200 \mathrm{~km}$, thick. The elastic lithosphere thickness is often roughly associated with an isotherm thereby acknowledging the temperature dependence of mantle rheology. From the definition of the lithosphere base as an isotherm, the surface heat flow again at the time of loading, can be estimated. The exact value of the basal temperature is a matter of debate but the assumed value of $925 \mathrm{~K}$ should be realistic. Zuber et al. (2000) arrive at heat flow values between $\sim 60 \mathrm{~mW} / \mathrm{m}^{2}$ for the southern hemisphere to values around a few tens of $\mathrm{mW} / \mathrm{m}^{2}$ at the time of loading of the Tharsis volcanoes. These values provide a coarse but interesting constraint for thermal evolution models.

\subsection{Composition, Moment of Inertia factor, and Structure}

The Martian or SNC meteorites (Nyquist et al., 2001) possess distinctive chemical compositions that hold clues for the composition of the planet as a whole and for the compositions and masses of the crust, mantle and core (Halliday et al., 2001). These basalts are not as depleted in $\mathrm{Fe}$ as terrestrial basalts and the Martian mantle appears to be twice as rich in $\mathrm{FeO}$ as the terrestrial mantle. On the basis of the SNC chemistry and assuming that Mars is overall chondritic in composition, Dreibus and Wänke (1985) estimated that the core comprises $\sim 20 \%$ of the planet's mass, and further suggested that the core contains about $15 \mathrm{wt}-\%$ sulfur.

The Martian mantle appears to have been more oxidizing than the Earth's mantle during core formation, because it is apparently not as depleted in moderately volatile elements as is the Earth. For example, the $\mathrm{K} / \mathrm{U}$ ratio of Mars is approximately 19,000 as compared with the Earth's K/U ratio of about 10,000 (Lodders, 1998). The $\mathrm{Th} / \mathrm{U}$ ratio should be about the same as on Earth, because both Th and $\mathrm{U}$ are refractory lithophile elements. $\mathrm{U}, \mathrm{Th}$, and $\mathrm{K}$ are the most important radioactive heat producing elements in a terrestrial planet's interior.

Despite the recent accurate measurement of the moment of inertia factor of Mars by Pathfinder (Folkner et al., 1997), present geophysical data do not constrain the interior structure of Mars unambiguously. Although a number of models have been published in the past two decades (for a recent review see Spohn et al., 1998), uncertainty persists mainly because of the small relative mass of the Martian core. The uncertainty can be illustrated by considering the simplest of models consisting just of an iron-rich core and a silicate shell. The three unknowns in this model, the core density and radius and the silicate shell density, are balanced by only two known quantities, the mass and the MoI-factor. The usual procedure is then to assume the core density and calculate the mantle density and the core radius. Even if we take the core composition to be constrained by the chemistry of the Martian meteorites and assign the core a concentration of $15 \mathrm{wt}-\%$ sulfur and a density of 


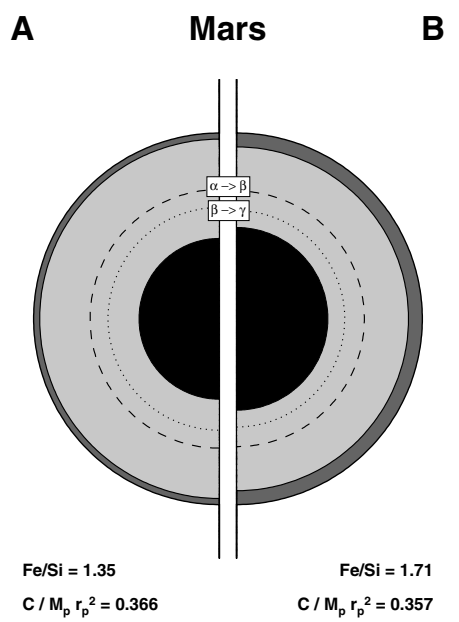

Figure 2. Comparison of the internal structure of Mars for a model $\mathbf{A}$ that satisfies the recent values of the MoI-factor and a model $\mathbf{B}$ that has a global solar Fe/Si value of 1.71. The global structures of the two models are similar with a basaltic crust, an upper and a lower mantle separated by the $\alpha$-olivine to $\beta$-spinel transition, and a metallic core. The lower mantle is further subdivided into $\beta$-spinel and very thin $\gamma$-spinel layers. The models differ significantly in the thickness of the crusts and the radii of the liquid cores. Fe/Si and $C / M_{\mathrm{p}} r_{\mathrm{p}}^{2}$ denote the calculated global iron to silicon ratio and the dimensionless polar moment of inertia factor, respectively.

$7000 \mathrm{~kg} / \mathrm{m}^{3}$ at standard pressure and temperature $\left(10^{5} \mathrm{~Pa}, 273 \mathrm{~K}\right)$, there will be an uncertainty in the latter value. If we assign an optimistic 5\% error and correct for compression, we get a core radius of $1700 \pm 200 \mathrm{~km}$, half the planetary radius, the accuracy will be $\sim 12 \%$, and the mass of the core is then $23 \pm 9$ wt- $\%$ of the planet's mass. The (average) silicate shell density of $3489 \mathrm{~kg} / \mathrm{m}^{3}$ is much better constrained, formally within $\sim 1 \%$. This density allows for a FeO-rich mantle composition.

These uncertainties have to be kept in mind, when we discuss more detailed models in the following. In Figure 2, two models of the present interior structure of Mars are compared using identical sets of material parameter values for crust, mantle, and core derived from Martian meteorite data (see Sohl and Spohn, 1997, for a more complete discussion). The first model (A) is consistent with the geophysical constraint of a polar moment of inertia factor of 0.3663 , while the second (B) satisfies the geochemical postulate of a chondritic bulk composition in terms of the bulk $\mathrm{Fe} / \mathrm{Si}$ ratio of 1.71. Model (A) gives a global ratio $\mathrm{Fe} / \mathrm{Si}=1.35$ and model (B) produces a polar moment of inertia factor of 0.357 . It is not possible on the basis of the present data to reconcile a $\mathrm{MoI}$ factor of 0.366 with the solar $\mathrm{Fe} / \mathrm{Si}$ value of 1.71 (see also Bertka and Fei, 1998).

The two models have a basaltic crust, an upper olivine-rich mantle, a lower spinel mantle further subdivided into $\beta$-spinel and $\gamma$-spinel layers, and an $\mathrm{Fe}$ rich core. The mineralogy is consistent with the sequence of phase assemblages stable in the Martian mantle at elevated temperatures and up to core-mantle boundary pressures obtained by Bertka and Fei (1997) from high-pressure and high- 
temperature experiments using synthetic mineral mixtures according to the mantle composition of Dreibus and Wänke (1985).

The locations of the olivine- $\beta$-spinel transition and the $\beta$-spinel to $\gamma$-spinel transition are similar in both models. (We will discuss below how phase transitions can have an effect on the evolution of the planet.) The pressure required for the phase transformations to take place is $13 \mathrm{GPa}$ at the $\alpha$-olivine- $\beta$-spinel transition and $18 \mathrm{GPa}$ at the $\beta$-spinel- $\gamma$-spinel transition. The olivine to $\beta$-spinel transformation is located at a depth of about $1000 \mathrm{~km}$, while the $\beta$-spinel to $\gamma$-spinel transition is situated several hundred kilometers above the core-mantle boundary. These transitions occur at a greater depth than in the Earth's mantle simply because of the smaller gravitational acceleration of Mars which results in lower pressures in the Martian mantle; the phase transitions are spread over a wider depth range because of the smaller pressure gradient.

The pressure at the core-mantle boundary is $\sim 22-23.5 \mathrm{GPa}$. It is lower than the pressure of the $\gamma$-spinel to perovskite phase transition (Chopelas et al., 1994) if the temperature is $<2100 \mathrm{~K}$. Since the $\gamma$-spinel to perovskite phase transition is strongly temperature dependent, a perovskite layer may have existed in early Mars when deep mantle temperatures were higher. Almost half of the bulk Fe by mass is in the core, which is found to be entirely liquid lacking a solid inner core and comprising $15 \%$ (model A) to $21 \%$ (model B) of the planet's mass. The core may be even smaller if it is solid or partly solid (although this may be inconsistent with the absence of a global magnetic field at present). For that case, recent data on the solid Fe-FeS system at high pressure and high temperature suggest a high-pressure, high-density phase change to a hexagonal NiAs superstructure (Fei et al., 1995). The core size would then only be $\sim 1400 \mathrm{~km}$, assuming a $\mathrm{S}$ content in the Martian core of 12 to $16 \mathrm{wt}-\%$, and a $\sim 200 \mathrm{~km}$ thick perovskite layer would be possible.

Figure 3 shows the density $\rho$ as a function of the radial distance from the planet's center. For both models the density varies similarly with depth despite differences in crust thicknesses and core radii. The density increases almost linearly with depth in the mantle and crust and parabolically in the core. There are prominent density discontinuities of $600 \mathrm{~kg} \mathrm{~m}^{-3}$ at the crust-mantle boundary and of $3000 \mathrm{~kg} \mathrm{~m}^{-3}$ at the core-mantle boundary. Phase transformations cause much smaller density discontinuities of $\sim 250 \mathrm{~kg} \mathrm{~m}^{-3}$ across the olivine- $\beta$-spinel transition and $\sim 130 \mathrm{~kg} \mathrm{~m}^{-3}$ across the $\beta$-spinel- $\gamma$-spinel transition.

\subsection{Geologic History, Volcanism, and Tectonics}

\subsubsection{Geologic History}

The geologic history of Mars is reviewed by Head et al. (2001) and will only be briefly outlined here. Three major stratographic time systems are used to characterize the geologic history, the Noachian, Hesperian and Amazonian (Tanaka et al., 1992). The assignment of absolute ages to the epochs is based on crater density measurements and is dependent on modeled cratering rates. The new synthesis 


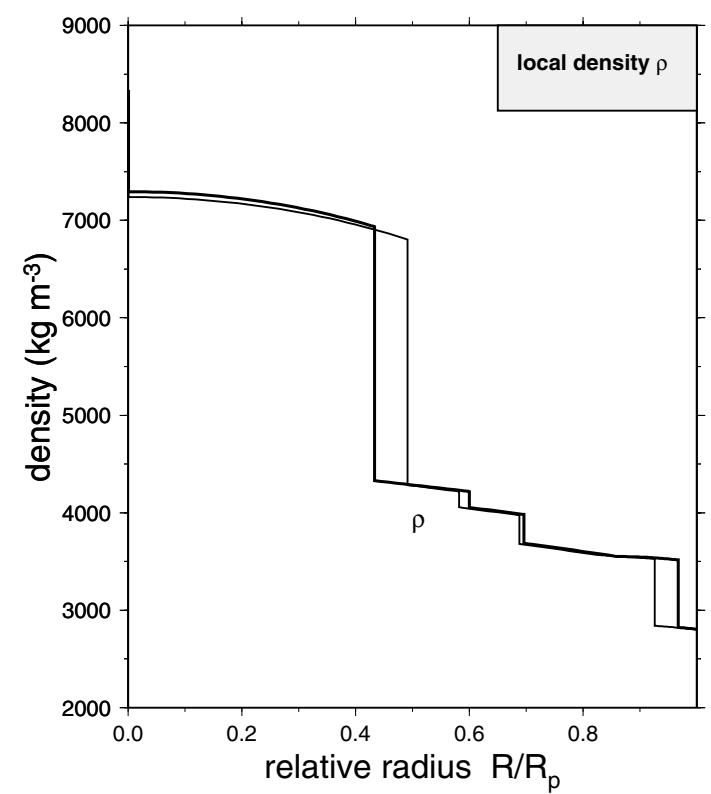

Figure 3. Radial distribution of density for model A (bold-lined) and model $\mathbf{B}$ (thin-lined). Note that there is little difference between crust and mantle densities in the two models despite of significant differences in crust thicknesses and core radii.

by Hartmann and Neukum (2001) places the Amazonian-Hesperian boundary at $2.9-3.3$ Gyr ago and the Hesperian-Noachian boundary at 3.5 - 3.7 Gyr ago.

Most of the southern highland units are of Noachian and Early Hesperian age. However, younger units of Amazonian age are exposed in small areas. The northern plains are younger than the southern highlands and range in age from Upper Hesperian to Upper Amazonian (Tanaka et al., 1992). The plains are diverse in origin: Most common around the volcanic centers of Tharsis and Elysium are lava plains with clearly developed flow fronts. However, the vast majority of the northern plains lack direct volcanic characteristics but are textured and fractured in a way that has been attributed to the interaction with ground ice and sedimentation as a result of large flood events, finally modified by wind (Carr, 1996). Nevertheless, it is believed that most of the Martian surface in particular the Northern lowlands are of volcanic origin (e.g., Greeley and Spudis, 1978; Tanaka et al., 1988; Mouginis-Mark et al., 1992; Greeley et al., 2000).

\subsubsection{Volcanism}

It has been argued that the entire surface of Mars may be of volcanic origin (e.g., Tanaka et al., 1988) but Tharsis and Elysium are undoubtedly the two most prominent volcano provinces on Mars. The three large Tharsis volcanoes Arsia, Pavonis and Ascraeus Montes are oriented along the southwest-northeast tending top of the bulge with their summits $27 \mathrm{~km}$ above the datum. Olympus Mons, the largest 
volcano in the solar system is located on the northwest flank of Tharsis. Each volcano has a large and complex summit caldera, and lava flows and channels are visible all over Tharsis. The large volcanoes seem to be formed by lava with only little pyroclastic activity (Pike, 1978; Plescia and Saunders, 1979; Tanaka et al., 1992); the smaller volcanoes on Tharsis show the same characteristics as the bigger ones. The flanks of the volcanoes exhibit lava flows with only a few superimposed impact craters indicating a very young age, whereas extended flows between the large volcanoes are older. The huge dimension of the Tharsis complex and the high effusion rates of Martian volcanoes (Greeley and Spudis, 1978) demonstrate that volcanism was an ongoing process throughout the planet's history (Neukum and Hiller, 1981; Tanaka et al., 1992) up to the recent ( $<100 \mathrm{Myr})$ past, as interpretation of data from the Mars Observer Camera (MOC) on MGS suggest (Hartmann et al., 1999; Hartmann and Berman, 2000; Hartmann and Neukum, 2001). Alba Patera to the north of Tharsis has the largest areal extent but rises just a few km above the surrounding surface. The flanks of Alba Patera are dissected by young branching valleys, which are interpreted as evidence for easily erodable pyroclastic deposits such as ash (Wilson and Mouginis-Mark, 1987). Similar channeled deposits have been observed at Hecates Tholus in Elysium and Tyrrhena Patera in the highlands. Thus, the Martian volcanism seems to have experienced quiet effusion of lava and to some extent also violent pyroclastic eruptions. The Elysium volcanoes are smaller but similar to those on Tharsis.

Geological mapping of the areal extent of volcanic deposits through time (Greeley and Schneid, 1991), coupled with estimates of the thickness of the deposits, enabled an estimation of the volume of volcanic materials produced on Mars of $6.86 \times 10^{7} \mathrm{~km}^{3}$. These authors assumed a ratio of intrusive to extrusive materials of 8.5 to 10 (based on values for the Earth) and estimated a total magma volume of $6.54 \times 10^{8} \mathrm{~km}^{3}$. This volume is equivalent to a global layer of $4.5 \mathrm{~km}$ thickness, $\sim 10 \%$ of the likely minimum thickness of the crust estimated from the gravity data. For the 3.8 Gyr age-span (mostly Hesperian to Amazonian) of the volcanic materials analyzed, this gives a magma production rate of $\sim 0.17 \mathrm{~km}^{3} \mathrm{yr}^{-1}$. However, there are uncertainties in these estimates due to poorly constrained values for thickness and uncertainties in the intrusive to extrusive ratio. The recent identification in MOC images of extensive thin layering in the walls of Valles Marineris suggests that volcanism in the Noachian has been much more extensive than previously recognized (McEwen et al., 1999). If these layers are indeed flood lavas and are representative globally, their volume will increase the estimated magma volume by an order of magnitude and bring the thickness of the layer close to the minimum crust thickness estimate from gravity! Furthermore, if most of this volcanism is Noachian in age as suggested by the mapping, the volcanic output would have peaked in the Noachian with a general decrease with time. 


\subsubsection{Tectonics}

Mars tectonics centers on Tharsis, the single largest tectonic entity in the solar system. Tharsis is surrounded by radial extensional rifts and grabens and concentric compressional wrinkle ridges that extend thousands of kilometers from its center. Most grabens on Mars are narrow (a few kilometers wide) and tens to hundreds of kilometers long structures bounded by inward dipping normal faults. Wider and deeper structures, more analogous to rifts on the Earth that rupture the entire lithosphere, can also be found in Tempe Terra, Valles Marineris and Thaumasia. Wrinkle ridges, linear to arcuate asymmetric topographic highs, are the most common compressional structures and form patterns of distributed compressional deformation. Large compressional ridges and buckles with greater strain in Noachian terrain to the south and southwest of Tharsis have also been suggested (Schultz and Tanaka, 1994). The total circumferential strain at a radius of $2500 \mathrm{~km}$ from the center of Tharsis is estimated to be $\sim 0.4 \%$, not accounting for buried structures, however (Banerdt and Golombek, 2000, and references therein).

Mapping of geologic and tectonic features (e.g., Wise et al., 1979, Tanaka et al., 1992, Banerdt et al., 1992) within the stratigraphic framework of Mars has revealed that the area has been active throughout most of the history of the planet. Its complex structural history involves 5 stages of tectonic activity at Tharsis with changes in the derived centers of activity through time (e.g., Anderson et al., 2000). More than half of the structures mapped have Noachian age (stage $1 ;>3.8-4.3 \mathrm{Gyr}$ ), and are exposed in Tempe Terra, Ceraunius Fossae, Syria Planum, Claritas Fossae, Thaumasia, and Sirenum. By Late Noachian-Early Hesperian (stage 2), activity was concentrated in Thaumasia and Valles Marineris. Middle Hesperian (stage 3 ) included the development of concentric wrinkle ridges concentrated along the edge of the topographic rise, although wrinkle ridges may have continued to form later due to global compression (e.g., Tanaka et al., 1991). Normal faulting also occurred north of Alba, in Tempe Terra, in Ulysses Fossae, in Syria Planum and Valles Marineris, and in Claritas Fossae and Thaumasia. Stage 4 activity during the Late Hesperian-Early Amazonian was concentrated in and around Alba Patera. Middle to Late Amazonian activity (stage 5) was concentrated on and around the Tharsis Montes volcanoes. These events all produced radial grabens centered at slightly different locations (local centers of volcanic and tectonic activity) within the highest standing terrain of Tharsis. This indicates most importantly that the basic structure of Tharsis has changed little since the Middle to Late Noachian (Anderson et al., 2000).

Lithospheric deformation models based on the Mars Global Surveyor gravity and MOLA topography appear to have simplified the stress states required to explain most of the tectonic features around Tharsis (Banerdt and Golombek, 2000). Flexural loading stresses based on present day gravity and topography appear to explain the location and orientation of most tectonic features. This observation coupled with the mapping results which suggest that more than half of the radial structures formed by the Middle to Late Noachian, argues strongly that the basic 


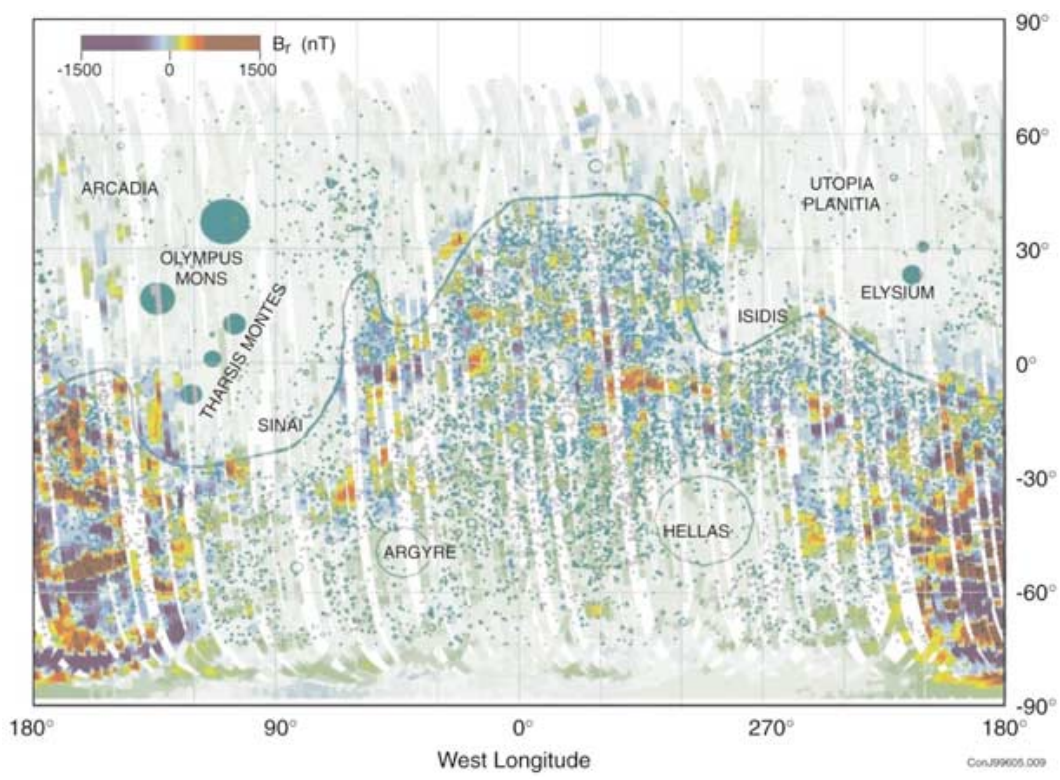

Figure 4. Magnetic field map of Mars compiled from MGS data (Acuña et al., 1999).

structure of the bulge has probably changed little since the Middle/Late Noachian. The lithospheric deformation models and the mapping require a huge load, of the scale of Tharsis, to have been in place by the Middle Noachian. This load likely was formed by Noachian volcanic extrusions. The load appears to have produced a flexural moat, which shows up most dramatically as a negative gravity ring, and an antipodal dome that explains the first order topography and gravity of the planet (Phillips et al., 2001). Many ancient fluvial valley networks, which likely formed during an early warmer and wetter period on Mars, flowed down the present largescale topographic gradient, further arguing that Tharsis loading was very early. This agrees with Figure 15c of Hartmann and Neukum (2001), which shows an order of magnitude decrease in the volcanic resurfacing rate $\left(\mathrm{km}^{2} / \mathrm{yr}\right)$ after the Noachian.

\subsection{MAGNetism}

The MAG/ER investigation flown on Mars Global Surveyor has established conclusively that Mars does not currently possess a magnetic field of internal origin and reported the discovery of strongly magnetized regions in its crust (compare Figure 4), closely associated with the ancient, heavily cratered terrain of the highlands south of the dichotomy boundary (Acuña et al., 1998, 1999). Evidence for a magnetic history of Mars did not come entirely unexpected, though. Models of Mars' interior and thermal evolution (Stevenson et al., 1983; Schubert and Spohn, 1990; Spohn, 1991; Spohn et al., 1998) predicted the existence of a thermal convection driven dynamo for at least the first billion years after accretion. Prior to the arrival of MGS at Mars the remnant magnetization of Martian meteorites had 
already suggested that the planet may have had in its past a surface magnetic field comparable in magnitude to that of the Earth (Curtis and Ness, 1988) and different regions of the Martian crust could have been magnetized with varying strengths and orientations representative of prior epochs of magnetic activity (Leweling and Spohn, 1997). Spacecraft missions prior to MGS, established that the current global magnetic field, if one existed at all, is weak with a surface field strength of less than $50 \mathrm{nT}$. A recently improved estimate of the upper limit to the magnitude of the current Mars dipole moment derived from the MGS data yields $M \leq 2 \times 10^{17} \mathrm{~A} \mathrm{~m}^{-2}$ which corresponds to a surface equatorial field strength of $\leq 0.5 \mathrm{nT}$.

Complementing the discovery of crustal magnetism at Mars, the MGS MAG/ER experiment observed linear patterns of strikingly intense magnetization in the southern hemisphere $(\sim 1600 \mathrm{nT}$ at $h=100 \mathrm{~km})$, particularly over Terra Sirenum and Terra Cimmeria (Connerney et al., 1999). These linear magnetic structures or "magnetic lineations" are clearly visible in Figure 4 and have been interpreted to result from processes similar to those associated with seafloor spreading at Earth. This association would imply that some form of plate tectonics and magnetic field reversals existed in Mars' early history. However, the sharp magnetization contrast required by the model of Connerney et al. (1999) suggests that alternative explanations involving the fracturing of a magnetized, thin crustal layer by tectonic stresses perhaps associated with the Tharsis rise may also be considered.

We cannot claim that the magnetization pattern of the Martian crust and its implications for the thermal evolution of the planet are fully understood. However, the MGS observations show that the majority of the crustal magnetic sources lie south of the dichotomy boundary on the ancient, densely cratered terrain of the highlands and extend $\sim 60^{\circ}$ south of this boundary. The formation of the dichotomy boundary should simply be interpreted to postdate the cessation of dynamo action. The absence of detectable crustal magnetization north of the dichotomy boundary in spite of a widespread record of active volcanism and magmatic flows suggests that dynamo action had ceased at this stage of crustal formation.

The southernmost limit of the crustal magnetization region appears to be associated with the destruction or modification of the magnetized crust by the impacts that created the Argyre and Hellas basins. The magnetic field observations acquired over the Hellas, Argyre and other impact basins indicate the presence of weak fields most likely of external origin, suggesting that the dynamo had ceased to operate when these basins were formed. It is estimated (e.g., Hartmann and Neukum, 2001, and references therein), that the Hellas and Argyre impacts took place less than about $300 \mathrm{Myr}$ after Mars accretion was completed and therefore Mars dynamo cessation should coincide or predate this epoch if this interpretation is correct. The distribution of magnetization suggests that processes that took place after the cessation of dynamo action only modified the ancient, magnetized, thin crust through deep impacts, magmatic flows, tectonics or reheating above the Curie point. Weaker crustal magnetic sources detected in the northern hemisphere (Acuña et al., 1999) are located in the younger, Amazonian plains and dipole models 
(Acuña et al., 1998; Ness et al., 1999) tend to yield source depths in excess of $100 \mathrm{~km}$ close to the estimated depth to the Curie isotherm in this region (Smith et al., 2000; Zuber et al., 2000).

The above interpretation of the magnetic record of Mars has recently been criticized by Schubert et al. (2000). These authors note that the punching of a homogeneously magnetized southern highlands crust should have left characteristic magnetic anomalies. While this is correct, it should be noted that the dissipation of impact energy may have resulted in heating and thermal demagnetization of a much extended region with the effect that the expected anomaly pattern there would have been lost. In any case, the authors are correct in pointing out that a high spatial resolution measurement of the magnetic field is required to fully solve the puzzle of the origin of its peculiar pattern.

\section{Interior Evolution}

\subsection{ACCRETION, EARLY DIFFERENTIATION AND CORE FORMATION}

Unraveling a planet's evolution is a difficult task that requires an integration of evidence from various fields into consistent models. Starting with the earliest times, it is now widely accepted that Mars formed by homogeneous accretion (Halliday et $a l ., 2001)$. The time required for a planet to differentiate into a core, mantle, crust and atmosphere/hydrosphere depends on the basically unknown conditions in the early planet. Most accretion scenarios result in hot planets possibly with magma oceans (e.g., Benz and Cameron, 1990). Several isotopic chronometers applied to Martian meteorites have provided evidence of very early isotopic heterogeneity caused by differentiation and preserved within Mars to the present day. Most importantly, Chen and Wasserburg (1986) showed using the $\mathrm{Pb}$ isotopic systematics of Shergottites, that Mars formed a core early.

The time span of accretion and the time of core formation can be more directly and accurately studied using the newly developed ${ }^{182} \mathrm{Hf}-{ }^{182} \mathrm{~W}$ chronometer (e.g., Lee and Halliday, 1997; Halliday et al., 2001). Hafnium and W are strongly fractionated by the processes of melting and core formation with $\mathrm{W}$ being much more incompatible than $\mathrm{Hf}$ and, consequently, with $\mathrm{W}$ being enriched in the melt and depleted in the residue. Some of the Martian meteorites have anomalously high concentrations of ${ }^{182} \mathrm{~W}$, the daughter product of ${ }^{182} \mathrm{Hf}$ (measured with respect to ${ }^{184} \mathrm{~W}$ ). These anomalies must have formed after the core had separated and $\mathrm{W}$ had been depleted. Evidently the accretion and differentiation of Mars was complete within a few Hf halflives or $20 \mathrm{Myr}$ (Lee and Halliday, 1997). On the Earth, the isotopic record suggests that core formation took substantially longer.

There are other striking differences between the Earth and Mars in the W isotope data. Since Martian meteorites nearly all formed long after ${ }^{182} \mathrm{Hf}$ became extinct, the variations of $\mathrm{W}$ isotopic abundances in the meteorites observed today indicate that the meteorite source regions must have somehow preserved these 
ancient heterogeneities. In the Earth $4.5 \mathrm{Gyr}$ of convection has stirred the mantle sufficiently to eliminate all trace of very early heterogeneity. In contrast, the Martian mantle has heterogeneities that can only have been produced in the first $50 \mathrm{Myr}$ of the solar system. Thus, mantle mixing must have been far less effective on Mars or the source regions of some SNC meteorites must have escaped vigorous mixing, as has been concluded earlier from $\mathrm{Sr}$ isotope data (e.g., Jagoutz et al., 1994)

The $\mathrm{W}$ data display a very significant relationship with the ${ }^{146} \mathrm{Sm}-{ }^{142} \mathrm{Nd}$ data (Harper et al., 1995) for the same Martian meteorites. This striking agreement provides a powerful insight into the early development of Mars. In order to generate a correlation between the $\mathrm{W}$ and $\mathrm{Nd}$ isotopic data, the two parent-to-daughter element ratios must have fractionated together at an extremely early stage. Lee and Halliday (1997) have interpreted these data as evidence of coeval, co-genetic and very early silicate melting and metal segregation (core formation). Although the source regions of the Martian meteorite parent magmas appear to have suffered early depletion from melting and core formation they yield no sign of the corresponding enriched reservoirs. This would be consistent with the outer portions of Mars representing a depleted residue or floating cumulate layer from which early enriched melts and metals segregated inward toward the center of the planet. However, the existing dataset is based on a very small number of samples.

A strong relation between core formation and silicate melting is also suggested from the physics of core formation. It has been argued (e.g., Stevenson, 1990) that the separation of iron melt from a silicate matrix is difficult, if not impossible because the melt would form isolated pockets instead of connected networks. This is a consequence of the surface energy of iron melt in comparison with the surface energy of silicate rock. The ratio between the surface energies is more favorable of iron segregation if there is silicate melt. However, Bruhn et al. (2000) have shown that iron can form a connecting network and flow if the solid silicate matrix is subject to shear such as would be provided by large-scale convective overturn.

In conclusion, the evidence from Martian meteorite isotope variations strongly argue for a hot early evolution with rapid core formation accompanied by early mantle melting and, perhaps, differentiation. The mantle differentiation may have led to chemical mantle layering which has perhaps drawn too little attention to date by scientists who model the mantle dynamics.

\subsection{Evolution AFter CORE Formation}

Since planets can be regarded as heat engines that convert thermal energy to mechanical work and magnetic field energy, the evolution of the planet subsequent to formation and early differentiation is strongly coupled to its thermal evolution or cooling history. The thermal evolution, in turn, is strongly related to the dynamics of the planet's mantle. Despite the arguments against mantle mixing above, there is little doubt that at least a significant part of the Martian mantle should have been convecting for most of if not all of its history. The argument is based on a 
comparison between the radiogenic heat production rate in the silicate shell and the heat transfer rates provided by heat conduction and thermal convection (e.g., Tozer, 1967; Stevenson and Turner, 1979). Given that the thermal conductivity of silicates is small, a few $\mathrm{W} / \mathrm{mK}$, heat production by radioactive elements even at their present concentrations after 4.5 Gyr of decay should lead to large scale planetary melting. However, the strongly temperature dependent viscosity of the mantle rock will decrease as the temperature increases, and even more so as partial melting begins, to allow large scale thermal convection driven by the temperature difference between the deep interior and the surface or between the deep interior and the temperature at the base of rigid lithosphere. Heat transfer by convection is generally thought to be efficient enough to eventually remove the heat generated by radioactives and to cool the interior. Partial melting will lead to the growth of the crust thereby further differentiating the silicate shell and transferring heat sources to the crust. The latter occurs because the radiogenic elements are lithophile due to their large ionic radii and valence states and tend to be enriched in the melt.

\subsection{Planform of Mantle Convection}

The planform of convection, the pattern of flow in the Martian mantle, remains speculative. Intuitively, it appears natural that the surface distribution of major tectonic and volcanic units at present and over time should somehow reflect the flow at depth. For instance, Matyska et al. (1998) have analyzed the distribution of volcanoes on the Martian surface and have related the latter to possible planforms of mantle convection. Moreover, the origin and genesis of the dichotomy is ascribed variously either to long-wavelength mantle convection (Wise et al., 1979) or to the flow associated with post-accretional core formation (Davies and Arvidson, 1981) sweeping up most of the crustal material into one large protocontinental mass. The MOLA topography (Smith et al., 2000) shows no trace of a giant impact that could have caused the dichotomy (Wilhelms and Squyres, 1984). Most recently, Zhong and Zuber (2001) proposed that the dichotomy and the crust thickness variation was the result of a degree-1 mantle convection planform. A low order convection pattern may also be suggested by the $\ell=2$ pattern of the topography (Section 2.1). In return, it has been speculated that a dichotomy in crustal thickness between the northern and southern hemispheres may have caused large scale differences in the mantle convection pattern underneath these hemispheres (Breuer et al., 1993) with consequences for crustal evolution. The dominance and stability of Tharsis and its continued activity until the recent past suggests that it may have been formed by a super-plume or a family of large plumes. The recent findings on the origin and history of Tharsis (Section 2.3.3) are consistent with a superplume but do not require the plume to be existent under Tharsis throughout Martian history (W. Banerdt, personal communication). This superplume must have supplied lava in the Noachian with an enormous rate. 


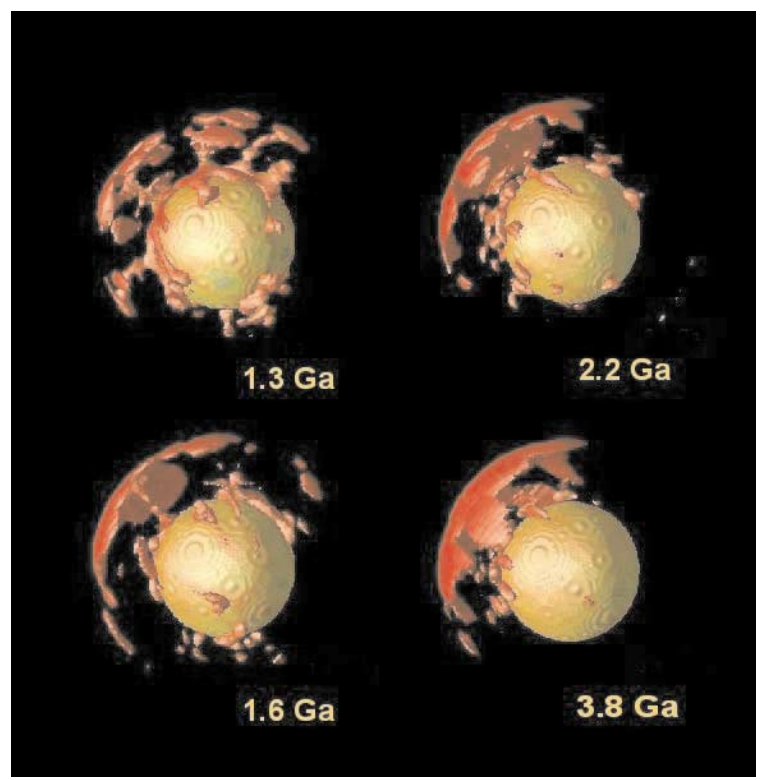

Figure 5. 3D mantle convection model showing plumes and their interaction with the ol-sp mantle phase transitions after Breuer et al. (1997). As can be seen from the figure, the model starts out with a number of small scale plumes. With the passage of time, the number of plumes is reduced and a super-plume survives. A similar evolution will be found as a consequence of the interaction of the flow with the spinel-perovskite transition.

Numerical convection modeling by Weinstein (1995), Zhou et al. (1995), Harder and Christensen (1996), Breuer et al. (1996, 1997, 1998) and Harder (2000) have suggested that the interaction of the olivine-spinel and, more strongly and more directly, the spinel-perovskite phase transformations with the mantle flow may suppress small, less energetic plumes and amplify large scale, strong plumes and thus force the upwelling flow into a small number of super-plumes. Figure 5 shows a series of snapshots from a 3D mantle convection calculation that illustrates the formation of a super-plume. The time scale of superplume formation in the calculation may be considered too long. However, this is mostly caused by an unrealistically low vigor of convection in the calculation forced by limitations in present day computer power. In early Mars the formation of the plume would probably have been about an order of magnitude faster.

The calculations of Martian mantle convection with phase transformations assumed that the temperature at the base of the mantle or the heat flow from the core was constant in time, assumptions often made for simplicity in numerical mantle convection calculations. However, recent 2D and 3D calculations, to be reported in detail elsewhere, that relax this assumption and allow the core to cool, cast some doubt on the applicability of these models to the entire thermal history. If the constant thermal boundary condition is relaxed and if the core is allowed to cool, it is found that the plumes decrease in strength on a time scale of a few $100 \mathrm{Myr}$ 
depending on the initial superheat of the core. Eventually the plumes fade away in step with the decrease of the heat flow from the core. The flow in the mantle is then increasingly dominated by downwelling plumes and broad upwelling flow as it is commonly found in internally heated convection experiments and calculations. These results suggest that the thermal evolution of the Martian interior after an initial phase of plume convection may basically be independent of mantle phase transitions. Plumes may persist for longer times only if the core provides additional heating. The amount of this heating is, however, expected to be small compared to the heat produced by radioactive elements in the mantle.

\subsection{Thermal History Models using Parameterized Convection}

Thermal evolution calculations with $2 \mathrm{D}$ or 3D mantle convection codes are very time-consuming on present-day computers. Therefore, to calculate thermal histories, convective heat transfer is often parameterized by relating the heat flow to the convective vigor through a suitable scaling law. The models are particularly useful if it can be assumed that the flow is simple in nature and that complications such as those that arise from interactions of the flow with phase transitions can be ignored. Early models have simply applied scaling laws derived from constant viscosity convection experiments. For the Earth with plate tectonics the parameterization seems to work quite well. These models were also applied to one-plate planets such as Mars (e.g., Stevenson et al., 1983) and later modified to include the effects of a growing lithosphere (Schubert and Spohn, 1990; Schubert et al., 1992; Spohn, 1991), using an equation for lithosphere growth first proposed by Schubert et al. (1979). The base of the lithosphere in these models is an isotherm assumed to be characteristic for the transition from viscous deformation to rigid response to loads applied over geologic time scales. A representative value of this temperature is $\sim 10^{3} \mathrm{~K}$. Heat transfer through the lithosphere is by heat conduction.

In recent years, experimental and numerical studies (e.g. Richter et al., 1983; Davaille and Jaupart, 1993; Solomatov, 1995; Moresi and Solomatov, 1995; Grasset and Parmentier, 1998) have improved our understanding of convection in layers of fluids with strongly temperature dependent rheologies. In these layers, a socalled stagnant lid will form beneath the cold surface and above a convecting sub-layer. The convection in the sub-layer is driven by the temperature difference across it. The viscosity variation in the sub-layer is small, only one to two orders of magnitude. Most of the viscosity variation occurs in the stagnant lid. For such a lid to form, the rate of change of viscosity $\eta$ with temperature $T,-d \ln \eta / d T$ times the temperature difference $\Delta T$ across the entire layer must be larger than $\sim 10$ (Solomatov, 1995). For commonly assumed mantle rheology parameters (e.g., Turcotte and Schubert, 1982) and Martian deep mantle temperatures the product is much larger than 10 placing the planet squarely in the field of stagnant lid convection.

The temperature at the base of the stagnant lid $T_{\mathrm{b}}$ (the top temperature is the surface temperature of the planet) can be expressed in terms of the temperature of the 


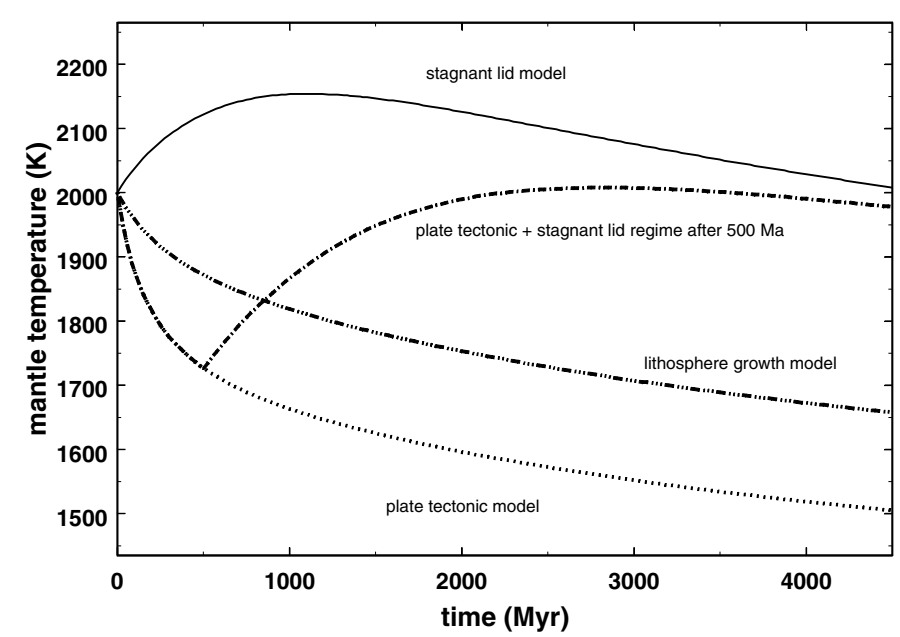

Figure 6. Thermal histories calculated for 4 different mantle heat transfer models

convecting sub-layer. If the latter is $T_{\mathrm{i}}$, then $T_{\mathrm{b}}$ is approximately $T_{\mathrm{i}} /\left(2.3 R T_{\mathrm{i}} / E+1\right)$ where $R$ is the universal gas constant and $E$ is the activation enthalpy for creep. Choosing representative values for $T_{\mathrm{i}} \approx 1800 \mathrm{~K}$ and $E \approx 400 \mathrm{~kJ} / \mathrm{mole}$, the difference between $T_{\mathrm{i}}$ and $T_{\mathrm{b}}$ is small, of the order of $100 \mathrm{~K}$. Thus, the stagnant lid contains the rheological lithosphere and is likely to be much thicker then the latter. Heat transfer through the lid again is by heat conduction.

A problem with the stagnant lid model, however, is that it may be ignoring some important aspect of mantle convection since the Earth also meets the criteria for stagnant lid convection but instead has plate-tectonics. Although it is universally accepted that at least present day Mars lacks plate-tectonics there may be other modes of efficient heat removal that we just have no way of appreciating at the present time. It has been speculated that Mars went through a phase of early plate tectonics: Sleep (1994) proposed that the Northern lowlands were formed in a phase of early Martian plate tectonics and that the Tharsis volcanoes may be the remnants of an island arc volcanic chain. Connerney et al. (1999) proposed that plate tectonics caused the stripe pattern of magnetic anomalies over Terra Sirenum and Terra Cimmeria, and Nimmo and Stevenson (2000) invoked plate tectonics to explain the early magnetic field of Mars altogether.

There are some important differences between models using these different parameterization schemes (Figures 6 and 7). Thermal history calculations applying the stagnant lid parameterization scheme show that the stagnant layer will thicken as the planet cools while the temperature of the convecting sub-layer will change comparatively little. In a series of evolution calculations with 2D and 3D convection models for the Moon, Spohn et al. (2001) have confirmed these principles by finding that the model lunar mantle cooled mostly by thickening its stagnant lid. 


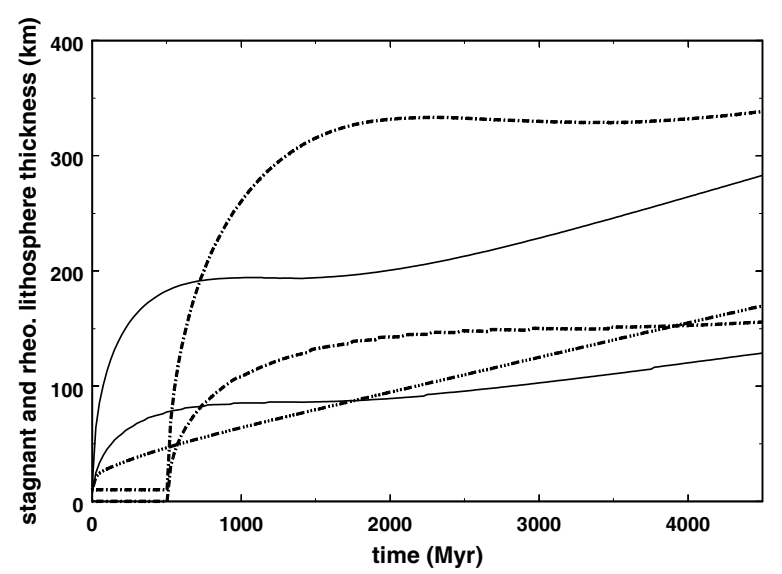

Figure 7. Lithosphere and stagnant lid thickness for 3 of the heat transfer models of Figure 6 . The solid lines are for the stagnant lid model; the lower curve gives the thickness of the lithosphere characterized by a $1075 \mathrm{~K}$ isotherm, and the upper plots the thickness of the stagnant lid. The dash-dotted lines are for the plate tectonics model that transfers into a stagnant lid model after $500 \mathrm{Myr}$. The dash-triple dotted line refers to the lithosphere growth model with a basal temperature of $1075 \mathrm{~K}$.

Figures 6 and 7 include a model with an early 500 Myr long phase of plate tectonics that transitions into the stagnant lid regime. The model is ad-hoc in the timing of the transition just as the Nimmo and Stevenson model. It is unclear how to model this transition and why the planet should undergo the transition in the first place. With plate tectonics there is no lid thickening and the cooling of the deep interior is most efficient. However, as the figures show, the model compensates the increased deep mantle cooling caused by plate tectonics through warming thereafter and the lack of lid thickening in the first 500 Myr through increased thickening. The lithosphere thickening model is inbetween the two extremes.

Figures 8 and 9 compare the surface heat flows and the accumulated heat removed from the models. It is interesting to note that these quantities fail to differ significantly between the models. Therefore, plate tectonics is not cooling the entire planet more effectively. The difference between the models is mostly a difference between cooling of the outer and the deeper layers. Plate tectonics cools the deep interior most effectively while stagnant lid convection cools the outer layer most effectively but cools the deep interior least effectively. It is further interesting to note that the surface heat flow shown in Figure 8 is consistent with the estimates of Zuber et al. (2000) based on gravity and topography modeling. Of the three models, the stagnant lid model is closest to the Zuber et al. estimate because the surface heat flow shows the smallest variation over the past $4 \mathrm{Gyr}$.

Geochemical heterogeneity may persist in the upper mantle due to stagnant lid convection because this mode removes a sizable fraction of the silicate shell from convective mixing. For lid thicknesses of up to $350 \mathrm{~km}, 100 \mathrm{~km}$ thickness is equivalent to approximately $10 \%$ of silicate shell volume. Figure 7 suggests that the 


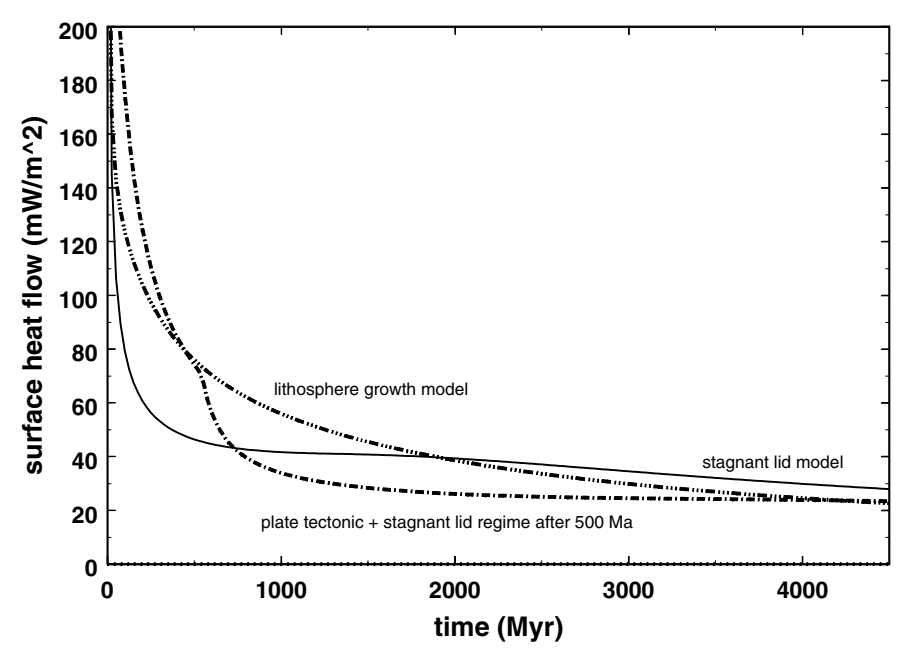

Figure 8. Surface heat flow calculated for the lithosphere growth model, the stagnant lid model, and the model with plate tectonics followed by stagnant lid convection.

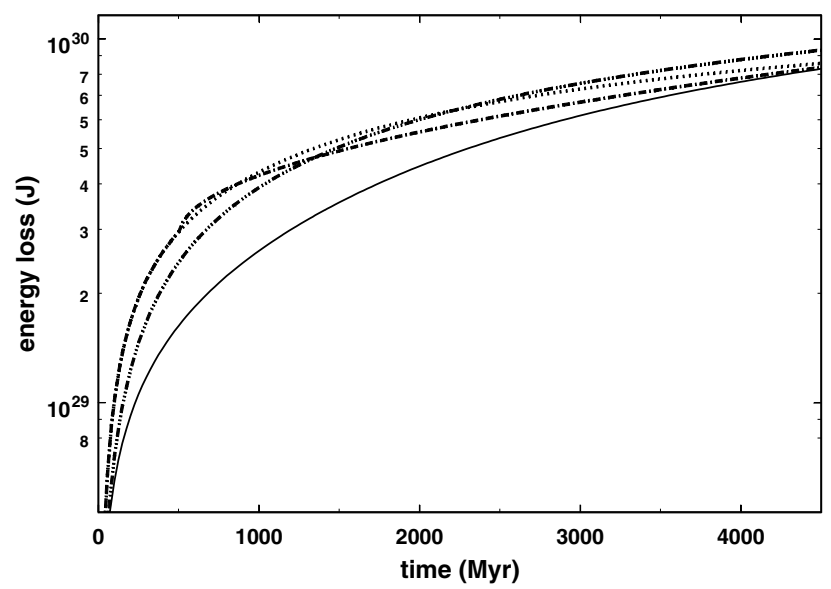

Figure 9. Cumulative heat flow calculated for the stagnant lid model (solid line), the lithosphere growth model (dash-triple dotted line), and the model with plate tectonics followed by stagnant lid convection (dash dotted line).

lid grows quickly initially. It may already be $100 \mathrm{~km}$ thick at the end of the overturn that accompanies core formation. The lid could contain the depleted reservoir and Martian meteorite source region required by the geochemical data.

\subsubsection{Crust Formation}

Parameterized convection models can easily be extended to include a model of crust growth (e.g., Spohn, 1991; Schubert et al., 1992). The mechanism of crust growth in these models may differ to some extent but typically depend on the vigor of mantle convection and on the concentration of the crustal component in the 


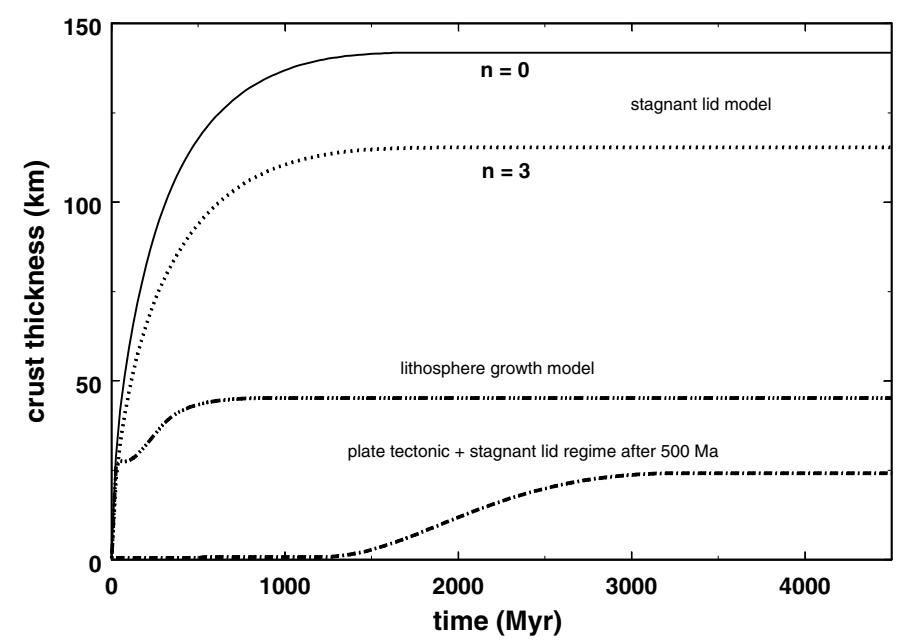

Figure 10. Crust thickness calculated for 3 models of Martian heat transfer through mantle convection, the lithosphere growth model (dashed line), the stagnant lid model (solid line), and model with plate tectonics followed by stagnant lid convection (dotted line).

mantle. In Figure 10 we show crustal thicknesses recently calculated by Breuer and Spohn (2001a, 2001b) for the stagnant lid, lithosphere growth, and plate tectonics models that additionally relate the growth rate to the degree of melting of the mantle and the thickness of the lid. The crust growth rate is given by

$$
\frac{d D_{\mathrm{c}}}{d t}=\frac{D_{\mathrm{pot}}-D_{\mathrm{c}}}{D_{\mathrm{m}}} u m_{\mathrm{a}}\left(1-\frac{D_{\mathrm{l}}}{D_{\mathrm{cr}}}\right)^{n},
$$

where $D_{\mathrm{c}}$ is the thickness of the crust, $t$ is time, $D_{\text {pot }}$ the maximum crustal thickness for complete separation between crustal reservoir and residue assumed to be $200 \mathrm{~km}, D_{\mathrm{m}}$ the thickness of the mantle, $u$ the mean mantle flow velocity calculated from the Rayleigh number to the power of $2 / 3, m_{\mathrm{a}}$ the mean melt concentration in the mantle i.e. the degree of partial melting, $D_{1}$ the thickness of the stagnant lid, $D_{\text {cr }}$ a critical depth, below which the melt cannot rise to the surface, and $n$ an exponent that accounts for the increasing frustration of melt transfer through the growing lid with increasing thickness. A value of $D_{\text {cr }}$ of $600 \mathrm{~km}$ has been assumed. The pressure at this depth is equivalent to the pressure where the density of magma due to compression becomes equal to the mantle density (Stolper et al., 1981). The use of $n$ is certainly ad-hoc, albeit reasonable in its effect on the crustal growth rate. For $n=3$, for example, only $\sim 60 \%$ of the melt will pass through a stagnant lid of $100 \mathrm{~km}$ thickness. The remainder will be intruded into the lid. The melt concentration $m_{\mathrm{a}}$ has been obtained by intersecting the solidus of the mantle material with the calculated mantle temperature profile. A linear increase of degree of melting between the solidus and the liquidius of the mantle has been assumed.

As Figure 10 shows, the crust grows fast to its final thickness within $\sim 1 \mathrm{Gyr}$ for the stagnant lid and the lithosphere growth models. The growth rate of the crust 
decreases with time in these models mainly because $m_{\mathrm{a}}$ decreases with temperature and with time. The final crustal thickness is strongly model-dependent; the stagnant lid model provides the thickest crust of $\sim 140 \mathrm{~km}$. If the crustal growth rate is assumed to decrease with increasing lid thickness $(n>0)$, the final thickness will be smaller. The stagnant lid model produces the thickest crust because of the higher mantle temperatures predicted by this model (Figure 6).

The plate tectonics model includes crustal growth only after the cessation of plate tectonics thereby assuming that crust produced by plate tectonics will be recycled. Since plate tectonics cools the mantle such that it is subsolidus $\left(m_{\mathrm{a}}=0\right)$ at the time of the transition to the stagnant lid regime, it takes $\sim 700 \mathrm{Myr}$ for the mantle to warm again and partially melt. Then, the crustal production rate begins to increase and peaks at $\sim 2$ Gyr. The present-day crust is a factor of 2 and 6 thinner than for the lithosphere growth and the stagnant lid models, respectively.

Crustal growth will act to additionally cool the mantle by moving heat sources from the mantle to the crust. In the stagnant lid and lithosphere growth models, this will lead to thicker lids and lithospheres with time. For the models presented in Figure 10, these layers are up to $100 \mathrm{~km}$ thicker as for the models in Figure 7. An important parameter that determines the final thickness of the crust, the lithosphere, and the lid is the initial temperature which is assumed to be $2000 \mathrm{~K}$ as in Figure 6 . With an initial mantle temperature of $1800 \mathrm{~K}$ a present-day crust thickness of only $70 \mathrm{~km}$ is obtained for the stagnant lid model. In this case, the crust production rate does not decrease continuously with time as in Figure 10 but shows a weak peak after $\sim 1$ Gyr, as Tanaka and Davis (1988) also have suggested on the basis of geologic data. Further parameters that determine the crustal evolution are the rheology parameters and the mantle thermal conductivity (Breuer and Spohn, 2001a, b).

The Martian meteorite compositions, in particular those of the Shergottites, the Pathfinder analyses, and the results of TES on MGS suggest at least two crustal types for Mars: Basalt and a more fractionated, more silica-rich andesitic type. According to the TES results, basalts appear to be mostly restricted to the southern hemisphere, while the andesites are prominent in the northern hemisphere but are also found in the south (Bandfield et al., 2000). It seems possible that both types are derived by partial melting of mantle rock and fractional crystallization in magma chambers. However, it is also possible that the andesitic rocks are produced by remelting of basalt. This may have occurred through an earlier phase of plate tectonics on Mars or through crust (partial) remelting. For instance, if the Tharsis bulge is indeed a gigantic volcanic pile, as the MGS results suggest, then it appears possible that the lower layers of this pile were eventually remolten to produce a more fractionated magma.

The calculations presented above do not include effects of crust reservoir recycling. An attempt at modeling the growth of two reservoirs has been presented by Breuer et al. (1993). The present results show that the Martian mantle may produce a voluminous crust during approximately the Noachian. The crust growth rate actually may differ locally. Heterogeneities in crust and upper mantle structure 
may focus a substantial part of the melt in a region such as Tharsis. It has been speculated, for instance by Watts et al. (1991), that the Hellas impact may have caused fracturing and may have triggered or enhanced volcanic activity in the Tharsis region. The net crust growth rate may be reduced by crust recycling with the mantle as through a phase of plate tectonics, but other mechanisms of recycling such as crust delamination may work as well locally. A further growth limiting factor is the frustration of melt transfer by lid growth. Large scale crust growth will cease as the planet cools and as the mantle becomes subsolidus $\left(m_{\mathrm{a}}=0\right)$ on average. However, this is not to say that volcanism should cease altogether. Even in an on average sub-solidus mantle, melt and volcanic activity may occur locally. The rate of melt production should, however, be small compared to the early activity.

\subsubsection{Core Convection and the Dynamo}

The observation of strong remnant crustal magnetization by the MGS-mission suggests a strong, self-generated magnetic field very early in Martian history. The much weaker magnetization of the SNC meteorites may indicate a weaker magnetic field at the time of the crystallization of their parent magmas $\sim 1$ Gyr ago.

It is widely accepted that a planetary magnetic field is produced by regenerative dynamo action in a fluid or partly fluid iron-rich core. The dynamo is thought to be driven by vigorous thermal or chemical convection. Thermal convection in the core like thermal convection in the mantle is driven by a sufficiently large superadiabatic temperature difference between the core and the mantle. Because the core fluid is of comparatively low viscosity ( $\sim 1 \mathrm{Pas})$, the required temperature differences are much smaller than those between the mantle and the surface required to drive mantle convection. The necessary temperature differences arise naturally when mantle convection removes heat from the core at a sufficiently large rate. This heat flow must be larger than the heat flow supplied by thermal conduction along the core adiabat. The latter heat flow therefore serves as a criterion for the existence of thermally driven convection in the core. The critical value of core heat flow depends on the adiabatic temperature gradient in the core and on the thermal conductivity. Nimmo and Stevenson (2000) have recently estimated the critical heat flow for Mars to be $\sim 5-20 \mathrm{~mW} / \mathrm{m}^{2}$.

Figure 11 shows the heat flow from the Martian core as a function of time calculated from the above thermal history models. The heat flow is below the critical value for thermal convection and thermally driven dynamo action at the present time for all models. This result has been previously obtained from similar calculations (Stevenson et al., 1983; Schubert and Spohn, 1990; Spohn, 1991). In early Martian history, the models predict dynamo action for periods of some $100 \mathrm{Myr}$ to $\sim 1$ Gyr depending on model details such as the initial temperatures and rheology of mantle and core, and the style of heat transfer. Thus, the models are consistent with estimates of the history of the Martian magnetic field that are based on the absence of magnetization in Hellas to suggest that the field had ceased to be produced by the time of formation of the Hellas and Isidis basins (Acuña et al., 1999). Note that 


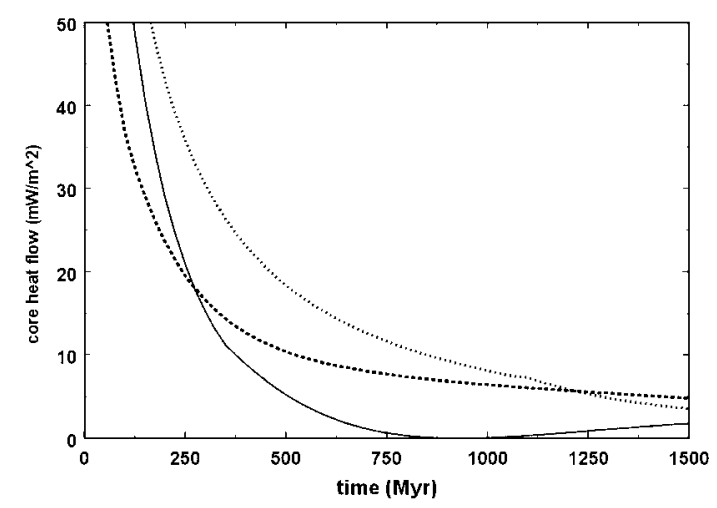

Figure 11. Core heat flow calculated for three models of heat transfer through Martian mantle convection, the lithosphere growth model, the stagnant lid model, and the model with plate tectonics followed by stagnant lid convection.

the stagnant lid model in particular and the lithosphere thickening model to a lesser degree require a substantial initial temperature difference between the core and the mantle because in these models cooling of the planet's deep interior is ineffective. This temperature difference may arise from a superheating of the core during core formation. Stevenson (1990) and Nimmo and Stevenson (2000) have argued that this superheating may be difficult to obtain because the $\mathrm{Fe}$ in the initial iron-silicate mixture may be finely distributed, and the Fe may be expected to be in thermal equilibrium with the silicates. Plate tectonics bring cold, near surface temperature material to the base of the mantle and cool the core more effectively than the other forms of heat transfer discussed above. The plate-tectonics model will have the least difficulty in explaining the strong early magnetic field of Mars. However, it is possible that the core contains some radiogenic heat sources as is thought to be possible for the Earth (e.g., Zindler and Hart, 1986; Breuer and Spohn, 1993)

Chemical convection can drive a dynamo more effectively than thermal convection (e.g., Braginsky, 1964; Stevenson et al., 1983). While the conversion of thermal energy to magnetic field energy has a Carnot efficiency factor such as any other heat engine, a chemically driven dynamo has no similar restriction in efficiency. Chemical convection may arise when a solid core freezes in a core that contains some light alloying element. Sulfur is usually taken as the most likely candidate because it is cosmochemically abundant and because of its chemical affinity to Fe. If the core has a non-eutectic composition, buoyant fluid will be released as the inner core grows at the surface of the inner core and will drive convection even if the core is stably stratified against thermal convection. Schubert and Spohn (1990) have concluded from their thermal evolution models that the Martian core is likely to be entirely liquid if it contains $\sim 15 \mathrm{wt}-\% \mathrm{~S}$, as data from the SNC meteorites suggest. A stagnant lid model predicts even greater temperatures in the lower mantle and core. A fluid core also results from the model with an early phase of plate tectonics. Thus a fluid core appears to be the simplest explanation for 
the present absence of a magnetic field at Mars and its early magnetization. Note, however, that inviscid solutions of an $\alpha \omega$ geodynamo (Jault, 1996) indicate that the dynamo action may be strongly impeded and strong-field solutions may be prohibited if an inner solid core grows larger than 0.35 of the core size.

Phase transitions in the Martian mantle and their interactions with the mantle flow may bring additional complexities to the evolution of the core and the magnetic field. Spohn et al. (1998) have discussed how a possible perovskite layer may affect the thermal history of the core. It is quite well established and has been substantiated by 2D and 3D convection calculations reported in Breuer et al. (1997) that the perovskite layer will actually reduce the heat flow from the core because the perovskite layer will form an additional (convective) layer between the mantle above and the core. Therefore, the hypothesis of an (early) perovskite layer will face the challenge of explaining the early strong dynamo if there was one. Core superheating during core formation and core heat sources are possibilities. The perovskite layer could provide an explanation for the magnetization of the Martian meteorites though. Their crystallization ages suggest that they were formed after the dynamo had been shut off. As discussed in Spohn et al. (1998) the perovskite layer may thin as the planet cools and eventually disappear because the transition is significantly temperature dependent. When the perovskite layer becomes so thin that it will no longer provide a barrier to the heat flow from the hot core, the heat flow may suddenly increase and may start or restart the dynamo thermally or perhaps even chemically. A thermally driven dynamo, as model calculations suggest, may operate for a few 100 Myr before it (again) becomes extinct. A chemically driven dynamo would, however, be likely to operate to the present day.

\section{Concluding Remarks}

We have discussed the evolution of Mars making use of the results of recent space missions, the chemistry of Martian meteorites and new insights into the physics of mantle convection. Some of the new results such as the gravity data and the magnetic field data cannot be unambiguously interpreted and certainly open new questions. Moreover, the confidence in our evolution models is still limited at present mostly because of our ignorance in some key areas such as dynamo theory, rheology and the interplay between convection and tectonics. Still an improved understanding of the evolution of Mars emerges: The history of Mars apparently proceeds from still little understood planet formation and rapid early differentiation by core formation and perhaps primordial crust formation to an early phase during which the planet was very active. Much of the major features on Mars such as, for instance, the Tharsis bulge was formed then. This period, basically the Noachian, was probably characterized by magnetic field generation, vigorous volcanic and tectonic activity, perhaps even plate tectonics, and a surface heat flow similar to the one of the present Earth's continents. Thereafter, the activity declined to reach the 
present day level. However, the recent past witnessed apparently more activity then was previously thought. This very likely includes recent volcanic activity.

Future missions to Mars have a high potential for providing missing information that will help to complete the story of the evolution of Mars. In addition to the outstandingly important task of providing an absolute scale for timing events in Martian history, completing the present day picture of Mars will be extremely helpful. Among the expected and much needed data are a determination of the core radius and the state of the core. Is the core entirely liquid or is there a solid inner core? Moreover, an absolute determination of crust thickness by seismology will help to anchor the crust thickness maps derived from gravity just as stratigraphy will be anchored by absolute age measurements. Similarly, a few heat flow measurements will anchor the heat flow estimates from gravity. The discovery of crustal magnetization on Mars, of course, motivates the desire for a further more detailed look with increased resolution. For modeling, we will need some increased effort to come to grips with the effects of rheology, partial melting, and chemical layering on the evolution of a planet. While our understanding of the effects of temperature dependent rheology on the heat transfer properties and the cooling history of the Martian interior are definite accomplishments it is disturbing that the only planet we know in detail does NOT behave the way the theory predicts. For the Earth, we have some, but not a complete understanding of why. For Mars, as well as for Mercury, Venus and any other of the earthlike planets and moons we do not even know whether or not these planets behave like the model predicts. A better knowledge of the interior structure will help.

\section{Acknowledgements}

We thank J. Geiss and R. Kallenbach of the International Space Science Institute for hosting the workshop, B. Hartmann and R. Kallenbach for their patient and thorough editing, and B. Jakosky and B. Hartmann for thoughtful reviews and constructive criticism. A significant part of this review was written while T. Spohn spent a sabbatical at UCLA. He thanks his colleagues at UCLA, in particular G. Schubert and M. Kivelson, for fruitful discussions.

\section{References}

Acuña, M.H., et al.:1998, 'Magnetic Field and Plasma Observations at Mars: Initial Results of the Mars Global Surveyor Mission', Science 279, 1676-1680.

Acuña, M.H., et al.: 1999, 'Global Distribution of Crustal Magnetism Discovered by the Mars Global Surveyor MAG/ER Experiment', Science 284, 790-793.

Anderson, R.C., et al.: 2000, 'Primary Centers and Secondary Concentrations of Tectonic Activity Through Time in the Western Hemisphere of Mars', J. Geophys. Res., in press. 
Bandfield, J.L., Hamilton, V.E., and Christensen, P.R.: 2000, 'A Global View of Martian Surface Compositions from MGS-TES', Science 287, 1626-1630.

Banerdt, W.B., Golombek, M.P., and Tanaka, K.L.:1992, 'Stress and Tectonics on Mars', in H.H. Kieffer, B.M. Jakosky, C.W. Snyder, and M.S. Matthews (eds.), Mars, Univ. Arizona Press, Tucson, pp. 249-297.

Banerdt, W.B., and Golombek, M.P.: 2000, 'Tectonics of the Tharsis Region, Insights from MGS Topography and Gravity', Proc. $31^{\text {st }}$ Lunar Planet. Sci. Conf., 2038.

Bertka, C. M. and Fei, Y.: 1997, 'Mineralogy of the Martian Interior up to Core-Mantle Boundary Pressures', J. Geophys. Res. 102, 5251-5264.

Bertka, C. M. and Fei, Y.: 1998, 'Density Profile of an SNC Model Martian Interior and the Moment of Inertia Factor of Mars', Earth Planet. Sci. Lett. 157, 79-88.

Benz, W., and Cameron, A.G.W.: 1990, 'Terrestrial Effect of the Giant Impact', in H.E. Newsom and J.H. Jones (ed.), Origin of the Earth, Oxford Univ. Press, Oxford, 61-67.

Braginsky, S. I.: 1964, 'Magnetohydrodynamics of the Earth's Core', Geomag. Aeron. 4, 698-712.

Breuer, D., and Spohn, T.: 1993, 'Cooling of the Earth, Urey Ratios, and the Problem of Potassium in the Core', Geophys. Res. Lett. 20, 1655-1658.

Breuer, D., Spohn, T., and Wüllner, U.: 1993. 'Mantle Differentiation and the Crustal Dichotomy of Mars', Planet. Space Sci. 41, 269-283.

Breuer, D., Zhou, H., Yuen, D.A., and Spohn, T.: 1996, 'Phase Transitions in the Martian Mantle: Implications for the Planet's Volcanic Evolution', J. Geophys. Res. 101, 7531-7542.

Breuer, D., Yuen, D.A., and Spohn, T.: 1997, 'Phase Transitions in the Martian Mantle: Implications for Partially Layered Convection', Earth Planet. Sci Lett. 148, 457-469.

Breuer, D., Yuen, D.A., Spohn, T., and Zhang, S.: 1998, 'Three Dimensional Models of Martian Mantle Convection with Phase Transitions', Geophys. Res. Lett. 25, 229-232.

Breuer, D., and Spohn, T.: 2001a, 'Thermal, Volcanic, and Magnetic Field History of Mars', Planet. Space Sci., submitted.

Breuer, D., and Spohn, T.: 2001b, 'Plate Tectonics Versus one-Plate Tectonics on Mars: Constraints From the Crustal Evolution', J. Geophys. Res., submitted.

Bruhn, D., Groebner, N., and Kohlstedt, D. L.: 2000, 'An Interconnected Network of Core-forming Melts Produced by Shear Deformation', Nature 403, 883-886.

Carr, M.H.: 1996, 'Water on Mars', Oxford Univ. Press, New York.

Chen, J.H., and Wasserburg, G.J.: 1986, 'Formation Ages and Evolution of Shergotty and its Parent Planet From U-Th-Pb Systematics', Geochim. Cosmochim. Acta 50, 955-968.

Chopelas, A., Boehler, R., and Ko, T.: 1994, 'Thermodynamics and Behavior of $\gamma-\mathrm{Mg}_{2} \mathrm{SiO}_{4}$ at High Pressure: Implications for $\mathrm{Mg}_{2} \mathrm{SiO}_{4}$ Phase Equilibrium', Phys. Chem. Min. 21, 351-359.

Connerney, J.E.P., et al.: 1999, 'Magnetic Lineations in the Ancient Crust of Mars', Science 284, 794-798.

Curtis, S.A., and Ness, N.F.: 1988, 'Remanent Magnetism at Mars', Geophys. Res. Lett. 15, 737-739.

Davaille, A., and Jaupart, C.: 1993, 'Transient High-Rayleigh-Number Thermal Convection With Large Viscosity Variations', J. Fluid Mech. 253, 141-166.

Davies, G.F., and Arvidson, R.E.: 1981, 'Martian Thermal History, Core Segregation, and Tectonics', Icarus 45, 339-346.

Dreibus, G., and Wänke, H.: 1985, 'Mars: A Volatile Rich Planet', Meteoritics 20, 367-382.

Fei, Y., Prewitt, C.T., Mao, H.K., and Bertka, C.M.: 1995, 'Structure and Density of FeS at High Pressure and High Temperature and the Internal Structure of Mars', Science 268, 1892-1894.

Folkner, W.M., Yoder, C.F., Yuan, D.N., Standish, E.M., and Preston, R.A.: 1997, 'Interior Structure and Seasonal Mass Redistribution of Mars From Radio Tracking of Mars Pathfinder, Science 278, 1749-1752.

Grasset, O., and Parmentier, E.M.: 1998, 'Thermal Convection in a Volumetrically Heated, Infinite Prandtl Number Fluid With Strongly Temperature-Dependent Viscosity: Implications for Planetary Thermal Evolution, J. Geophys. Res. 103, 18,171-18,181. 
Greeley, R., and Spudis, N.F.: 1978, 'Volcanism in the Cratered Terrain Hemisphere of Mars', Geophys. Res. Lett. 5, 453-455.

Greeley, R., and Schneid, B.D.: 1991, 'Magma Generation on Mars: Amounts/Rates, and Comparisons With Earth, Moon, and Venus', Science 254, 996-998.

Greeley, R., Bridges, N.T., Crown, D.A., Crumpler, L.S., Fagents, S.A., Mouginis-Mark, P.J., and Zimbleman, J.R.: 2000, 'Volcanism on the Red Planet: Mars', in J.R. Zimbelmann and T.K.P. Gregg (eds.), Environmental Effects on Volcanic Eruptions: from Deep Oceans to Deep Space, Kluwer Academic/Plenum Publ., New York, pp. 75-112.

Halliday, A.N., and Lee, D.-C.: 1999, 'Tungsten Isotopes and the Early Development of the Earth and Moon', Geochim. Cosmochim. Acta 63, 4157-4179.

Halliday, A.N., Birck, J.L., Clayton, R.N., and Wänke, H.: 2001, 'The Accretion, Composition and Early Differentiation of Mars', Space Sci. Rev., this volume.

Harder, H.: 2000, 'Mantle Convection and the Dynamic Geoid of Mars', Geophys. Res. Lett. 27, 301-304.

Harder, H., and Christensen, U.: 1996, 'A One-Plume Model of Martian Mantle Convection, Nature 380, 507-509.

Harper, C.L., Nyquist, L.E., Bansal, B., Wiesmann, H., and Shih C.-Y.: 1995, 'Rapid Accretion and Early Differentiation of Mars Indicated by ${ }^{142} \mathrm{Nd} /{ }^{144} \mathrm{Nd}$ in SNC Meteorites', Science 267, 213-217.

Harri, A.M., et al.: 2000, 'Network Science Landers for Mars', Adv. Space Res., in press.

Hartmann, W.K., and Berman, D.C.: 2000, 'Elysium Planitia Lava Flows: Crater Count Chronology and Geological Implications', J. Geophys. Res. 105, 15,011-15,026.

Hartmann, W.K., Malin M.C., McEwen, A., Carr, M., Soderblom, L., Thomas, P., Danielson, E., James, P., and Veverka, J.: 1999, 'Recent Volcanism on Mars from Crater Counts', Nature 397, 586-589.

Hartmann, W.K., and Neukum, G.: 2001, 'Cratering Chronoloy and the Evolution of Mars', Space Sci. Rev., this volume.

Hartmann, W.K., Kallenbach, R., Geiss, J., and Turner, G.: 2001, 'Summary: New Views and New Directions in Mars Research', Space Sci. Rev., this volume.

Head, J.W., Greeley, R., Golombek, M.P., Hartmann, W.K., Hauber, E., Jaumann, R., Masson, P., Neukum, G., Nyquist, L.E., and Carr, M.H.: 2001, 'Geological Processes and Evolution', Space Sci. Rev., this volume.

Jagoutz, E., Sorowka, A., Vogel, J.D., and Wänke, H.: 1994, 'ALH84001: Alien or Progenitor of the SNC Family', Meteoritics 28, 548-579.

Jault, D.: 1996, 'Sur l'Inhibition de la régénération du Champ Magnétique dans Certains Modèles de Dynamo Planétaire en Présence d'une Graine Solide', C. R. Acad. Sci. Paris 323, 451-458.

Lee, D.-C., and Halliday, A.N.: 1997, 'Core Formation on Mars and Differentiated Asteroids', Nature 388, 854-857.

Leweling, M., and Spohn, T.: 1997, 'Mars: a Magnetic Field due to Thermoremanence?', Planet Space Sci. 45, 1389-1400.

Lodders K.,: 1998, 'A Survey of Shergottite, Nakhlite and Chassigny Meteorites Whole-rock Compositions', Met. Planet. Sci. 33, A183-A190.

Longhi, J., Knittle, E., Holloway, J.R., and Wänke, H.: 1992, 'The Bulk Composition, Mineralogy, and Internal Structure of Mars', in H.H. Kieffer et al. (eds.), Mars, University of Arizona Press, Tucson, pp. 184-208.

Matyska, C., Yuen, D., Breuer, D., and Spohn, T.: 1998, 'Symmetries of Volcanic Distributions on Mars and its Interior Dynamics', J. Geophys. Res.,103, 28,587-28,597.

McEwen, A.S., Malin, M.C., Carr, M.H., and Hartmann, W.K.: 1999, 'Voluminous Volcanism on Early Mars Revealed in Valles Marineris', Nature 397, 584-586.

Moresi, L.N., and Solomatov, V.S.: 1995, 'Numerical Investigation of 2D Convection With Extremely Large Viscosity Variations', Phys. Fluids 7, 2154-2162. 
Mouginis-Mark, P.J., Wilson, L., and Zuber, M. T.: 1992, 'The Physical Volcanology of Mars', in H.H. Kieffer et al. (eds.), Mars, Univ. Arizona Press, Tucson, pp. 424-452.

Ness, N.F., et al.: 1999, 'MGS Magnetic Fields and Electron Reflectometer Investigation: Discovery of Paleomagnetic Fields due to Crustal Remanence', Adv. Space Res. 23, 1879-1886.

Neukum, G., and Hiller, H.: 1981, 'Martian Ages', J. Geophys. Res. 86, 3097-3121.

Nimmo, F., and Stevenson, D.J., 2000, 'Influence of Early Plate Tectonics on the Thermal Evolution and Magnetic Field of Mars', J. Geophys. Res. 105, 11,969-11,979.

Nyquist, K., Bogard, D., Shih, C.-Y., Greshake, A., Stöffler, D., and Eugster, O.: 2001, 'Ages and Geologic Histories of Martian Meteorites', Space Sci. Rev., this volume.

Phillips, R.J, et al.: 2001, 'Ancient Geodynamics and Global Scale Hydrology on Mars', Science, in press.

Pike, R.J.: 1978, 'Volcanoes on the Inner Planets: Some Preliminary Comparison of Gross Topography', Proc. $9^{\text {th }}$ Lunar Planet. Sci. Conf., 3239-3273.

Plescia, J.B., and Saunders, R.S.: 1979, 'The Chronology of the Martian Volcanoes', Proc. $10^{\text {th }}$ Lunar Planet. Sci. Conf., 2841-2859.

Reasenberg, R.D., Shapiro, I.I., and White, R.D.: 1975, 'The Gravity Field of Mars', Geophys. Res. Lett. 2, 89-92.

Richter, F.M., Nataf, H.C., and Daly, S.F.: 1983, 'Heat Transfer and Horizontally Averaged Temperature of Convection With Large Viscosity Variations', J. Fluid Mech. 129, 173-192.

Rieder, R., Economou, T., Wänke, H., Turkevich, A., Crisp, J., Brückner, J., Dreibus, G., McSween, H.Y., Jr.: 1997, 'The Chemical Composition of Martian Soil and Rocks Returned by the Mobile APXS: Preliminary Results from the X-ray Mode', Science 278, 1771-1774.

Schubert, G., Cassen, P., and Young, R.E.: 1979, 'Subsolidus Convective Cooling Histories of Terrestrial Planets, Icarus 38, 192-211.

Schubert, G., and Spohn, T.:1990, 'Thermal History of Mars and the Sulfur-Content of its Core', $J$. Geophys. Res. 95, 14,095-14,104.

Schubert, G., Solomon, S.C., Turcotte, D.L., Drake, M.J., Sleep, N.H.: 1992, 'Origin and Thermal Evolution of Mars', in H.H. Kieffer et al. (eds.), Mars, Univ. Arizona Press, Tucson, pp. 147-183.

Schubert, G., Russel C.T., Moore, W.B.L.: 2000, 'Timing of the Martian Dynamo', Science 408, 666-667.

Schultz, R.A., and Tanaka, K.L.: 1994, 'Lithospheric-Scale Buckling and Thrust Structures on Mars: The Coprates Rise and South Tharsis Ridge Belt', J. Geophys. Res. 99, 8371-8385.

Sleep, N.H.: 1994, 'Martian Plate Tectonics', J. Geophys. Res. 99, 5639-5655.

Smith, D.E., et al.: 1999a, 'The Global Topography of Mars and Implication for Surface Evolution', Science 284, 1495-1503.

Smith, D.E., Sjogren, W.L., Tyler, G.L., Balmino, G., Lemoine, F.G., and Konopliv, A.S.: 1999b, 'The Gravity Field of Mars: Results from Mars Global Surveyor', Science 286, 94-97.

Smith, D.E., et al.: 2000, 'Mars Orbiter Laser Altimeter (MOLA): Experiment Summary After the First Year of Global Mapping of Mars', J. Geophys. Res., submitted.

Sohl, F., and Spohn, T.: 1997, 'The Interior Structure of Mars: Implications from SNC Meteorites', J. Geophys. Res. 102, 1613-1635.

Solomatov, V. S.: 1995, 'Scaling of Temperature- and Stress-Dependent Viscosity', Phys. Fluids 7, 266-274.

Spohn, T.: 1991, 'Mantle Differentiation and Thermal Evolution of Mars, Mercury, and Venus', Icarus 90, 222-236.

Spohn, T., Sohl, F., and Breuer, D.: 1998, 'Mars', Astron. Astrophys. Rev. 8, 181-235.

Spohn, T., Konrad, W., Breuer, D., and Ziethe, R.: 2001, 'The Longevity of Lunar Volcanism: Implications of Thermal Evolution Calculations With 2D and 3D Mantle Convection Models', Icarus 149, 54-65.

Stevenson, D.J.: 1990, 'Fluid Dynamics of Core Formation', in H.E. Newsom and J.H. Jones (eds.), Origin of the Earth, Oxford Univ. Press, New York, pp. 231-250. 
Stevenson, D.J., and Turner, J.S.: 1979, 'Fluid Models of Mantle Convection',in M.W. McElhinny (ed.), The Earth, Its Origin, Evolution, and Structure, Wiley, New York, pp. 227-263.

Stevenson, D. J., Spohn, T., and Schubert, G.: 1983, 'Magnetism and Thermal Evolution of the Terrestrial Planets', Icarus 54, 466-489.

Stolper, E., Walker, D., Hager, B. H., and Hays, J. F.: 1981, 'Melt Segregation From Partially Molten Source Regions: The Importance of Melt Density and Source Region Size', J. Geophys. Res. 91 , 6261-6271.

Tanaka, K.L., and Davis, P.A.: 1988, 'Tectonic History of the Syria Planum Province of Mars', $J$. Geophys. Res. 93, 14,893-14,917.

Tanaka, K.L., Isbell, N.K., Scott, D.H., Greeley, R., and Guest, J.E.: 1988, 'The Resurfacing History of Mars', Proc. $18^{\text {th }}$ Lunar Planet. Sci. Conf., 665-678.

Tanaka, K. L., Golombek, M. P., and Banerdt, W. B.: 1991, 'Reconciliation of Stress and Structural Histories of the Tharsis Region of Mars', J. Geophys. Res. 96, 15,617-15,633.

Tanaka, K.L., Scott, D.H., and Greeley, R.: 1992, 'Global Stratigraphy', in H.H. Kieffer et al. (eds.), Mars, Univ. Arizona Press, Tucson, pp. 345-382.

Tozer, D.C.: 1967, 'Towards a Theory of Thermal Convection in the Mantle', in T.F. Gaskell (ed.), The Earths's Mantle, Academic Press, London, pp. 325-353.

Turcotte, D.L., and Schubert, G.: 1982, Geodynamics, Wiley, New York.

Treiman, A.H., Drake, M.J., Janssens, M.-J., Wolf, R., and Ebihara, M.: 1986, 'Core Formation in the Earth and Shergottite Parent Body (SPB): Chemical Evidence From Basalts', Geochim. Cosmochim. Acta 50, 1071-1091.

Wänke, H., and Dreibus, G.: 1988, 'Chemical Composition and Accretion History of Terrestrial Planets', Phil. Trans. R. Soc. Lond. A325, 545-557.

Wänke, H., Brückner, J., Dreibus, G., and Ryabchikov, I.: 2001, 'Chemical Composition of Rocks and Soils at the Pathfinder Site', Space Sci. Rev., this volume.

Watts, A.W., Greeley, R., and Melosh, H.J.: 1991, 'The Formation of Terrains Antipodal to Major Impacts', Icarus 93, 159-168.

Weinstein, S.A.: 1995, 'The Effects of a Deep Mantle Endothermic Phase Change on the Structure of Thermal Convection in Silicate Planets', J. Geophys. Res. 100, 11,719-11,728.

Wieczorek, M.A., and Phillips, R.J.:1998, 'Potential Anomalies on a Sphere: Applications to the Thickness of the Lunar Crust', J. Geophys. Res. 103, 1715-1724.

Wilhelms, D.E., and Squyres, S.W.: 1984, 'The Martian Hemispheric Dichotomy may be due to a Giant Impact', Nature 309, 138-140.

Wilson, L., and Mouginis-Mark, P.J.: 1987, 'Volcanic Input to the Atmosphere from Alba Patera on Mars', Nature 330, 354-357.

Wise, D.U., Golombek, M.P., and McGill, G.E.: 1979, 'Tectonic Evolution of Mars', J. Geophys. Res. 84, 7934-7939.

Zhou, H., Breuer, D., Yuen, D.A., and Spohn, T.: 1995, 'Phase Transitions in the Martian Mantle and the Generation of Megaplumes', Geophys. Res. Lett. 15, 1945-1948.

Zindler, A., and Hart, S.R.: 1986, 'Chemical Geodynamics', Ann. Rev. Earth Planet. Sci. 14, 493571.

Zuber, M.T., et al.: 2000, 'Internal Structure and Early Thermal Evolution of Mars from Mars Global Surveyor Topography and Gravity', Science 287, 1788-1793.

Zhong, S., and Zuber, M.T.: 2001, 'Degree-1 Mantle Convection and Martian Crustal Dichotomy', Nature, submitted.

Address for correspondence: Institut für Planetologie, Westfälische Wilhelms-Universität, W. Klemmstrasse 10, D-48149 Münster, Germany 